\title{
WILD BIDS. GAMBLING FOR RESURRECTION IN PROCUREMENT CONTRACTS*
}

\author{
Aleix Calveras $\dagger^{\dagger}$ Juan-Jose Ganuza ${ }^{\ddagger}$ And Esther HauK ${ }^{\S}$
}

APRIL, 2003

\begin{abstract}
This paper analyzes the problem of abnormally low tenders in the procurement process. Limited liability causes firms in a bad financial situation to bid more aggressively than financially healthy firms in the procurement auction. Therefore, it is likely that the winning firm is a firm in financial difficulties with a high risk of bankruptcy. The paper focuses on the regulatory practice of surety bonds to face this problem. We show that the use of surety bonds reduces and sometimes eliminates the problem of abnormally low tenders. We provide a characterization of the optimal surety bond and show that the US practice of requiring that surety bonds cover over $100 \%$ of the contract price can be excessive, implying overinsurance to the problem of abnormally low tenders.
\end{abstract}

KeYwords: Procurement, abnormally low tenders, limited liability and bankruptcy. JEL classification numbers: L51, H57, D44.

\footnotetext{
${ }^{*}$ We thank Fernando Garcia, Roberto Burguet, three anonymous referees and participants of the Asset Euroconference 2001 and the I Encuentro de Economia Industrial for helpful comments and suggestions. Calveras gratefully acknolwledges financial support from the Spanish Ministry of Science and Technology under CICYT grant BEC2001-2552-C03-03. Ganuza gratefully acknolwledges financial support from the Spanish Ministry of Science and Technology under DGES grant BEC 2000-1026. Hauk gratefully acknowledges financial supp ort from the Spanish Ministry of Science and Technology under DGES grant BEC 2000-1029 and a Ramon y Cajal grant.

${ }^{\dagger}$ Departament d'Economia de l'Empresa, Universitat de les Illes Balears, Cra. Valldemossa km 7, 07122 Palma de Mallorca (Balears), Spain.; fax +34-971 172389; aleix.calveras@uib.es.

${ }^{\ddagger}$ Department of Economics and Business, Universitat Pompeu Fabra, Carrer Ramón Trías Fargas, 23-27, 08005, Barcelona, Spain; fax: +34-93-542 1746; juanjo.ganuza@econ.upf.es.

${ }^{\S}$ Corresponding author: Department of Economics and Business, Universitat Pompeu Fabra, Carrer Ramón Trías Fargas, 23-27, 08005, Barcelona, Spain; fax: +34-93-542 1746; esther.hauk@econ.upf.es.
} 


\section{INTRODUCTION}

In a procurement process the administration or private sponsor sometimes receive a very low bid. Is this low price for the realization of a project always good news for the sponsor? Not necessarily. Although the low bid might be due to low costs of the firm or estimation mistakes made by the firm which the firm (and not the sponsor) will have to bear, very often this low bid is related to the strategic behavior of the firm during the auction. Some firms bid very aggressively because they expect to renegotiate the contract later on when it will be very costly for the sponsor to replace the incumbent firm (which causes cost overruns). Aggressive bids might also be due to firms in a bad financial state struggling for survival by taking a risky strategy. Such a strategy can be optimal because the owners and managers of these firms are protected by bankruptcy laws. To award the project to an insolvent firm with a high probability of bankruptcy is problematic since bankruptcy is very costly for the sponsor: bankruptcy implies delays in the completion of the project, litigation costs, the cost of the new procurement process, etc. We will use the term abnormally low tenders (ALTs) exclusively for this latter phenomenon. We do not study cost overruns, which have been modeled e.g. by Lewis (1986), Arvan and Leite (1990) and Ganuza (2000).

Abnormally low tenders are an important problem especially in the construction industry in which it is easy to close and reopen a business because everything can be subcontracted. For small or medium sized procurement projects the problem is aggravated because the market of potential contractors is big and little is known about each individual contractor. In the US during 1990-1997 more than 80,000 contractors went bankrupt leaving unfinished private and public construction projects with liabilities exceeding $\$ 21$ billion. ${ }^{1}$ According to the Associated General Contractors of America about one-half of today's construction firms will be out of business in six years. In Europe, the situation is not any better. In 1997 the European Union studied how to improve the competitiveness of the European construction industry and found that abnormally low tenders

\footnotetext{
${ }^{1}$ Dun \& Bradstreet Business Failure Record.
} 
were one of the main problems, and therefore became a priority issue. ${ }^{2}$

The first objective of the paper is to analyze the problem of abnormally low tenders from a theoretical point of view. In order to do so, we develop a simple model in which firms with identical costs but different financial positions compete in a second-price auction for a procurement project. ${ }^{3}$ In our model the procurement project has some uncertainty with respect to its costs. The attitude towards this uncertainty depends on each firm's financial position. Firms are protected by limited liability (bankruptcy laws). Therefore, the potential losses of firms with a good financial status are bigger than that of firms with a bad financial status, since some of the losses are not realized due to limited liability. Hence, firms in bad financial shape will behave as if they were risk loving and therefore bid more aggressively than firms in good shape. Consequently, it is very likely that a firm in a bad financial position will win the auction and then bankruptcy is probable.

The second objective of the paper is to evaluate some regulatory policies that different countries have developed to mitigate the problem of abnormally low tenders. We mainly study the so-called surety bonds, a system that is used in the US, Canada and Japan and is seriously considered by the European Community, given its relative success compared to the current European regulation. The surety bond is an instrument under which a specialized firm, the surety company, guarantees to the sponsor that the contractor will perform the procurement contract. In case of contractor's failure, both the contractor and the surety company are liable. The surety therefore helps the contractor to finish the construction project in case of difficulties. If this is too costly, the surety compensates the sponsor for the amount specified in the bond. In practice, sureties are regulated and required to have sufficient capital reserves to back the bonds they issue. ${ }^{4}$ Since sureties are responsible for completing the contract, they have strong incentives to screen potential contractors' technical ability and financial status.

It is shown that the introduction of a surety bond mitigates and sometimes eliminates the

\footnotetext{
${ }^{2}$ For more details see the report on the "Prevention, Detection and Elimination of Abnormally Low Tenders in the European Construction Industry" elaborated by DGIII Working Group on Abnormally Low Tenders in 1999.

${ }^{3}$ Procurement auctions are typically first price auctions. However, we use a second price auction since it simplifies the analysis and since it can be shown (as we argue later on) that these two types of auctions provide the same expected outcomes in our setup.

${ }^{4}$ For example in the US each surety company must be listed as a qualified surety on the Treasury List, which the US Department of Treasury issues each year.
} 
problem of abnormally low tenders. We also characterize how the optimal surety bond changes with the underlying parameters of the model and evaluate the effectiveness of the current US practice of requiring a surety bond equal to $100 \%$ of the contract price in the light of these results.

While to the best of our knowledge this is the first paper to model gambling for resurrection in the procurement process (i.e. in "reverse" auctions), the underlying intuition on why insolvent firms bid more aggresively than solvent firms is similar to that in the Corporate Finance literature (e.g. Shleifer and Vishney (1997)) where limited liability causes shareholders of risk neutral firms in financial distress to choose riskier projects. The problems of limited liability and default risk have recently also been discussed in the literature on standard ("forward") auctions. Waehrer (1995) analyzes a model with default risk where the winning bidder has an opportunity to cancel the transaction and pay prespecified damages to the seller. Limited liability is modeled by this security deposit chosen by the seller and - in contrast to our model - is identical for all bidders.

As far as we know the effect of different degrees of limited liability on bidding strategies was first noticed in some auction experiments, in which experimental subjects' losses were limited to zero, since experimenters did not want to ask the participants for money (see e.g. Hansen and Lott (1991) and Kagel and Levin (1991)). Hansen and Lott (1991) pointed out that this limited liability could lead to overbidding. Later, the FCC spectrum auctions revealed the need for an auction theory with budget-constraints (see e.g. McMillan, Rothschild and Wilson (1997)). However, most of the theoretical work on auctions with budget constrained bidders (e.g. Che and Gale $(1996,1998))$ did not consider default risk. The need to combine limited liability and default risk became very clear after the so-called C-block disaster: in 1996 the US government auctioned off a block of radio frequencies for around $\$ 10$ billion. The winning firms were allowed to delay payment at below market borrowing rates and no appropriate credit requirements were set on the bidders. Consequently, many bidders overbid relying on the possibility of renegotiation and the declaration of bankruptcy, which many of the winning bidders, including NextWave, Pocket Communications, General Wireless and Airadigm Communication, indeed did. Till today, most 
licences of the firms that defaulted remain wrapped up in bankruptcy litigations. ${ }^{5}$ Inspired by this C-block disaster Zheng (2001), in a paper which was independently written of ours, analyzes a first-price auction with limited liability and default risk. He also obtains the result that bidders with the lowest budget (assets in our model) may bid the most, since - as in our model- low budget bidders have less to lose from bankruptcy than high budget bidders. The main difference to our model is that bidders have access to outside financing at a constant borrowing rate which, in contrast to our paper, is identical for all bidders independently of their financial status. Aside from the differences in the modelling choices, our paper differs from Zheng's paper in that this author focuses on how the sponsor can improve his revenue in forward auctions by granting subsidies to bidders, while our paper analyzes different regulatory practices to face the problem of abnormally low tenders in procurement, with a special emphasis on surety bonds.

The remainder of the paper is organized as follows. In section 2 we describe the model and show why abnormally low tenders occur. In section 3 we introduce and analyze surety bonds. Section 4 provides a characterization of the optimal surety bond. We also study the US requirement that the surety bond equals the contract price. Section 5 discusses some further regulatory measures, and section 6 concludes. All proofs are relegated to a technical appendix.

\section{The Model}

Consider a risk neutral administration or sponsor who plans to undertake a public construction project of value $V$, where $V$ is large enough so that it is always optimal to build the project. There are $N$ risk neutral potential contractors in the market. All contractors have the same cost structure. For each potential contractor the cost of the project is $C_{P}=c+s$, with $c$ common knowledge, and $s=-k_{G}<0$ with probability $(1-q)$ and $s=k_{B}>0$ with probability $q$. We assume $c>k_{G} \cdot{ }^{6}$ Also, for sake of expositional simplicity, we assume that the expected cost of the project is $c$, i.e. $(1-q)\left(-k_{G}\right)+q k_{B}=0$. Contractors differ in their initial financial status

\footnotetext{
${ }^{5}$ For more details see Zheng (2001) and the references therein.

${ }^{6}$ Notice that if $c<k_{G}$ the total cost turns out to be negative if the shock is good.
} 
$A_{i} \geq 0$, which is the value of the firm in case the project is not realized by the firm. ${ }^{7}$

$A_{i}$ is private information of firm $i$. In practice, the sponsor is able to obtain some information on the the financial situation of the firm. However, a public sponsor (an administration) is usually restricted to the use of hard and verifiable information such as whether the firm is on current payment of social security and other liabilities like loans, and is not specialized in the screening of firms. A private sponsor does not have the former restriction but it also lacks the screening ability to clearly identify the financial situation of each firm. Thus, it is reasonable to assume that the true value of $A_{i}$ is, to a large degree, private information of firm $i$.

Construction firms have limited liability, i.e. they can avoid a negative financial status by closing down. Firm $i$ will close down if firm $i$ is awarded the project and $A_{i}$ plus the net profits from undertaking the project fall below 0 during the construction process. To be more precise, the financial value of the firm after the project is realized $\left(\Pi_{i}\right)$ is defined as follows:

$$
\begin{aligned}
& \Pi_{i}\left(x_{i}=0\right)=A_{i}, \\
& \Pi_{i}\left(x_{i}=1, P\right)= \begin{cases}0 & \text { if } A_{i}+P-c-s<0, \\
A_{i}+P-c-s & \text { otherwise }\end{cases}
\end{aligned}
$$

where $P$ is the procurement price and $x_{i} \in\{0,1\}$ indicates to whom the project is assigned. $x_{i}=1$ if and only if firm $i$ gets the project. We assume that the financial status of each firm is independently distributed on the interval $[0,+\infty)$ according to an arbitrary distribution function $F(\cdot)$.

The sponsor organizes a second price auction to procure the project. ${ }^{8,9}$ Therefore the firm with the lowest bid is awarded the project at the price of the second lowest bid. During the construction process the unknown cost parameter $s$ is realized and the firm either finishes the project or declares bankruptcy. As we said in the introduction, bankruptcy implies important

\footnotetext{
${ }^{7}$ This way of modeling bidder-heterogeneity is due to Che and Gale (1996) who model bidder-heterogeneity in terms of wealth instead of value in a forward auction. It is also used in Zheng (2001).

${ }^{8}$ The second price auction works as follows: firms present their bids, the firm with the lowest bid wins the auction at a price equal to the second lowest bid. The advantage of this auction is that it is a dominant strategy for the firms to bid the opportunity cost of building the project, independently of the features of the environment, such as the number of bidders, the distribution of the financial values of firms, etc. This property makes the analytical treatment of the paper a lot easier. For a good survey of the literature on auction theory, see Klemperer (1999).

${ }^{9}$ We have chosen the second-price sealed-bid auction for our model on the basis of simplicity and ease of presentation. It can be shown that in our setup the first-price and second-price auction yield the same expected outcome. A formal proof of this fact is available from the authors upon request.
} 
costs to the sponsor arising from the delays in the completion of the project, litigation costs, the cost of the new procurement process, etc. We denote these costs by $C_{B}$, with $C_{B}>0$. We assume that when the firm declares bankruptcy the sponsor has to bear the realized cost of the project plus this bankruptcy cost minus the liquidation value of the firm $A_{i}$. When the firm declares bankruptcy it cannot comply with the procurement contract and the sponsor can appropriate the firm's asset, if any. ${ }^{10}$ Thus, the utility of the sponsor is

$$
U_{S}= \begin{cases}V-P & \text { if the firm finishes the project } \\ V-c-s+A_{i}-C_{B} & \text { if the firm declares bankruptcy. }\end{cases}
$$

We now summarize the timing of the model:

1. Nature chooses the financial value $A_{i}$ of each firm.

2. The sponsor announces the procurement process. Firms present their bids.

3. The project is awarded to the firm with the lowest bid at a price equal to the second lowest bid. Ties are handled by using a lottery. Denote the assets of the winning firm by $A^{*}$. The winning firm starts constructing the project. The unknown cost parameter $s$ is realized. If $A^{*}+P-c-s>0$, the firm finishes the project. Otherwise it declares bankruptcy and the cost of finishing the project for the sponsor is $c+s+C_{B}-A^{*}$.

4. Sponsor and firms get their payoffs.

Given that in the model all contractors have the same cost function, the efficiency of the winning firm is not an issue in our framework. The main issue is to minimize both the procurement price and the probability of bankruptcy. In the next subsection we show that a simple auction mechanism, as the standard second price auction, does not optimally balance these two objectives.

\footnotetext{
${ }^{10}$ Sometimes the sponsor might prefer to help the firm who won the contract to finish the project, in order to avoid the bankruptcy process and its costs for the sponsor (delays, litigation costs). Allowing for this possibility does not alter our results (summarized in Proposition 2), which only require that transaction (bankruptcy) costs are positive.
} 


\subsection{Abnormally low tenders}

Under the standard second price auction the procurement process is similar to Bertrand competition among heterogeneous firms. Hence, the equilibrium bid of each firm $i$ is the minimum price $P_{i}^{*}$ for which firm $i$ is willing to accept the project, defined by:

$$
E\left\{\Pi_{i}\left(x_{i}=1, P_{i}^{*}\right)\right\}=A_{i}
$$

where $E\left\{\Pi_{i}\left(x_{i}=1, P_{i}^{*}\right)\right\}$ denotes the expected value of firm $i$ when it is awarded the project at a price $P_{i}^{*}$.

Firm $i$ wins the second price auction if and only if $P_{i}^{*}=\min \left\{P_{1}^{*}, \ldots, P_{i}^{*}, \ldots, P_{N}^{*}\right\}$, and will be paid $P=\min \left\{P_{1}^{*}, \ldots, P_{i-1}^{*}, P_{i+1}^{*}, \ldots, P_{N}^{*}\right\}$. Lemma 1 characterizes the equilibrium bid function.

Lemma 1 The equilibrium bid is

$$
P^{*}\left(A_{i}\right)= \begin{cases}c-k_{G}+\frac{q}{1-q} A_{i} & \text { if } 0 \leq A_{i}<k_{B}, \\ c & \text { if } A_{i} \geq k_{B}\end{cases}
$$

$P^{*}\left(A_{i}\right)$ is continuous and non-decreasing in $A_{i}$.

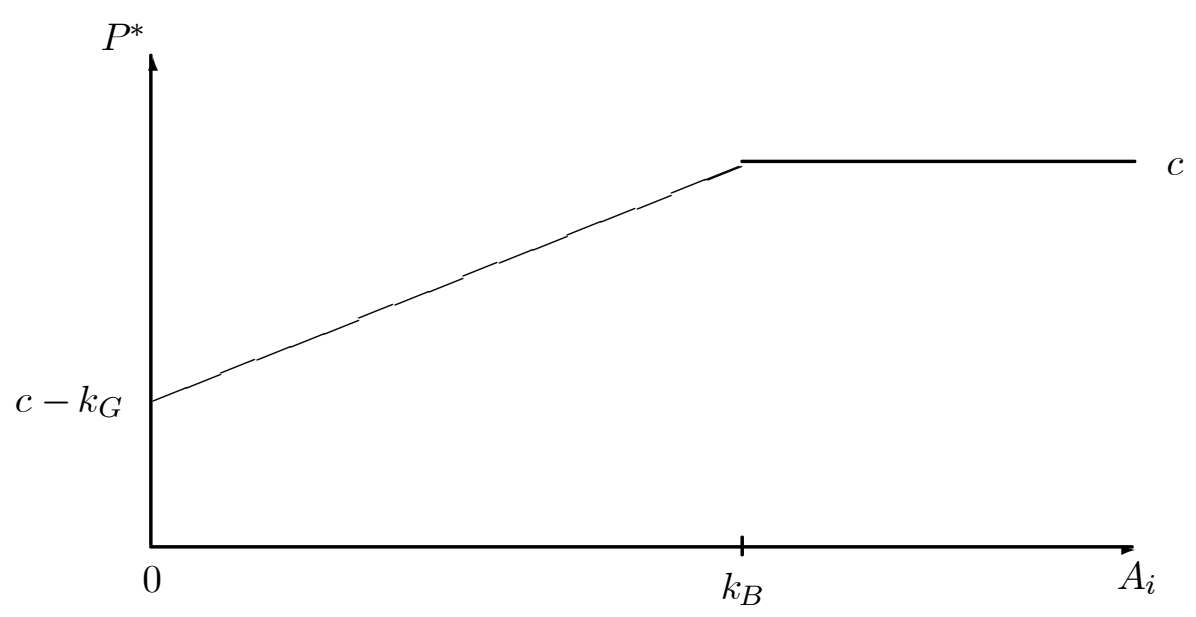

Figure 1: Bids as a function of the financial situation

Corollary 1 identifies the firms with some bankruptcy risk for the sponsor.

Corollary 1 The project is always finished if and only if the financial status of the winning firm is $A_{i} \geq k_{B}$. 
Given Corollary 1 and abusing terminology we will refer to all firms with $A_{i} \geq k_{B}$ as 'solvent' and all firms with $A_{i}<k_{B}$ who might go bankrupt as 'insolvent'. Any insolvent firm with $A_{i} \in\left[0, k_{B}\right)$ will bid more aggressively than solvent firms with $A_{i} \geq k_{B}$ because losses are limited by the amount of assets owned. Therefore, limited liability makes insolvent firms behave as if they were risk loving. Hence, the winning firm is not going to be solvent unless all firms are solvent. Bankruptcy is likely to occur.

This phenomenon that firms bid below costs is better known as abnormally low tenders. The main worry of the public administration or sponsor concerning abnormally low tenders is that when they occur, the probability of bankruptcy is high. Our model provides the argument why this happens: firms in bad financial shape gamble for resurrection; given that they have little to lose they bid very aggressively in the hope of a good realization of the shock. Straight from the Lemma 1, the following proposition identifies the type of firm that is awarded the contract.

Proposition 1 The second price auction awards the contract to an insolvent firm with $A_{i} \in$ $\left[0, k_{B}\right)$, provided there is some.

From the sponsor's point of view, the second price auction generates two countervailing effects. On one hand, aggressive bidding by firms is good because it reduces the price the sponsor has to pay. On the other hand, aggressive bidding increases the probability of bankruptcy of the winning firm. This second effect dominates. The bid of the insolvent firm is lower because the firm will not pay the construction costs of the project in case of a bad shock but declares bankruptcy instead. If this happens the sponsor will have to end up paying both bankruptcy and construction costs. If the sponsor could limit entry to the second price auction to solvent firms only he would like to do so. To see why, Lemma 2 considers the benchmark case of full information.

Lemma 2 With full information about the financial situation of bidding firms, the sponsor would be better off by awarding the contract to a solvent firm at its opportunity cost $c$ of taking the contract, rather than awarding the contract to an insolvent firm at its opportunity cost $c-k_{G}+$ $\frac{q}{1-q} A_{i}$ of taking the contract. 
The expected payment of the sponsor when awarding the project includes three components: (i) the expected cost of the project, (ii) the expected transaction costs (bankruptcy costs) and (iii) the profits of the firm awarded the contract. Thus, on one hand, since the expected cost of the project is the same for all firms, it is easy to see that with full information about the financial situation of bidding firms, the lowest payment is achieved when the winning firm is solvent, because then bankruptcy never occurs and thus transaction costs are zero, as opposed to the case in which the bidding firm is insolvent. Furthermore, the profits of the firm awarded the contract are zero in either case.

In other words, suppose there is at least one solvent and one insolvent firm willing to obtain the contract. Then, with full information the contract would be awarded to the solvent firm at its opportunity cost $c$, whereas with private information, the sponsor uses the second price auction and awards the contract to the more insolvent firm, incurring in a utility loss: in addition to the expected cost of the project, the sponsor will have to bear transaction costs when bankruptcy occurs and will have to pay informational rents to the winning insolvent firm. Thus, the sponsor faces an adverse selection problem when he awards the project using a simple auction mechanism such as the second price auction.

Moreover, such a problem might increase with fiercer competition. If there are $N$ firms the probability that the winning firm belongs to $A_{i} \in\left[0, k_{B}\right)$ and therefore might go bust is defined by $^{11}$

$$
\operatorname{prob}_{W}=1-\left[1-\left(F\left(k_{B}\right)-F(0)\right)\right]^{N}
$$

which increases in the number of firms $N$. This does not allow us to conclude that increasing competition is bad in reality, because we make the strong assumption in our model that costs are symmetric. With asymmetric costs increasing the number of firms might mean that a more efficient firm enters the market.

To summarize, the auction does not select an adequate firm. The sponsor therefore has to look for some instruments to reduce abnormally low tenders. As we have shown above the sponsor

\footnotetext{
${ }^{11}$ Recall that $F(\cdot)$ is the distribution function of the financial status of firms.
} 
will be better off by allowing only solvent firms to bid. However, this policy is not feasible for the sponsor as already explained when justifying our assumption that $A_{i}$ is private information of firms: the sponsor's screening process will either be imperfect or extremely costly. Therefore, it makes sense for specialized firms to handle the screening since their experience allows to reduce the screening costs and improve the efficiency of screening tools. This is exactly the role of the so-called surety companies. In the next section we discuss how requiring surety bonds in the procurement process will affect abnormally low tenders.

\section{SuREty Bonds}

A surety bond is a guarantee in which the surety company guarantees that the contractor will perform the obligation stated in the bond. ${ }^{12}$ We focus our analysis on 'performance bonds'. ${ }^{13} \mathrm{~A}$ performance bond guarantees the sponsor that the contractor will complete the contract according to its terms including price and time. If the contractor defaults, the sponsor may call upon the surety to complete the contract, or pay the bond. Performance bonds give the sureties three options: completing the contract itself (taking up the contract); selecting a new contractor to contract directly with the sponsor; or allowing the sponsor to complete the work with the surety paying the costs (up to the amount established in the surety bond). In practice, sureties are required to have enough capital to meet their bonding liabilities.

The surety evaluates the contractor and the contractor's work to decide whether it will bond

\footnotetext{
${ }^{12}$ Surety bonds were first introduced in the US in 1894 by the Heard Act in a time period when public construction work began to be important. In the late 19th century, anybody could qualify as a constructor: no specific education nor experience was required and start-up costs were very low. As a result, the construction sector was very big with many insolvent construction firms. The failure rates were high, and it was discovered that most firms that went bankrupt during the construction of a public project had been close to bankruptcy before winning the contract. To protect tax payers, the congress passed the Heard Act authorizing (requiring) the use of surety bonds on public construction projects. The Heard Act was replaced by the Miller Act in 1935. The Miller Act requires the contractor to provide surety bonds for all Federal construction contracts over $\$ 100,000$. For further details see http://www.sio.org/ (Surety Information Office), and Donohue and Thomas (1996).

${ }^{13}$ Besides performance bonds there are two other types of bonds: (i) bid bonds that assure the sponsor that the bidder will honor its bid and will sign all contract documents if awarded the contract. The bid bond is often ten to twenty percent of the bid amount; (ii) the payment bond that protects subcontractors and suppliers against default by the prime contractor. The payment bond often guarantees less than the total amount of the prime contract. In this paper we assume that the contract is always entered at the bid price and there are no subcontractors. Therefore, surety bonds in our model focus on performance bonds.
} 
that contractor. Since the surety guarantees the contractor's performance, the surety has strong incentives to decide whether the contractor has the ability and resources to perform. A surety's means of evaluating a contractor to decide if it will issue bonds is the underwriting process. During this process, the surety requires financial and technical statements from the firms and establishes the price of the bond accordingly. Potential customers usually have to provide the surety with their audited fiscal year-end statements including the balance sheet showing their net worth and an income and cash flow statement. The surety also wants to see their organizational chart with key personnel, business plan, growth and profit objectives, a list of completed jobs in the past and letters of recommendation. Typically, sureties are good at evaluating this information due to their specialization and experience.

Surety premia, i.e. the price contractors have to pay for the surety bond, usually are priced as a percentage of the size of the surety bond issued. However, the percentage itself is decided on an individual basis and reflects the surety's evaluation of the financial status of the firm. In the US, for example, the most financially secure contractors will pay the lowest bond premium. In the following subsection we will see that this is one of the features of the equilibrium pricing strategy of a surety.

\subsection{Modelling surety bonds}

We now introduce surety bonds in our framework. Assume that the sponsor requires a surety bond of size $L$ from the winning firm. Each firm will have to go to a surety company to apply for the bond covering the procurement price resulting from its bid. Surety companies screen firms and learn $A_{i}$. On account of their screening process, sureties can choose a different interest rate (premium or fee) $r_{i}$ for each firm. If the surety bond of size $L$ is granted, sureties have to freeze sufficient funds of their own to back it up. Alternatively, the surety company could invest $L$ in a riskless asset at interest rate $r_{0}$. Granting the surety bond is risky since firms might not be able to finish the project on their own. Should this happen, the surety has to intervene; it either helps the firm to finish the project or it pays $L$ to the sponsor. Clearly, the surety will do the latter 
when the cost for finishing the project exceeds $L$. We assume that surety companies are perfectly competitive, hence they make zero profit. Finally, with the introduction of a surety bond the utility of the sponsor is

$U_{S}= \begin{cases}V-P & \text { if the firm and the surety company finish the project }, \\ V-c-s+A^{*}-r_{i} L+L-C_{B} & \text { if the project is left unfinished. }\end{cases}$ where $A^{*}$ is the financial status of the winning firm. Thus, notice that when the project is left unfinished, the sponsor is paid $L$ by the surety, and confiscates $A^{*}-r_{i} L$ from the contractor. The sponsor finishes the project on its own (e.g. by means of a new procurement process), incurring the bankruptcy $\operatorname{costs} C_{B}$. The timing when a surety bond is required goes as follows:

1. The sponsor procures a project, requiring a surety bond of size $L$.

2. Firms negotiate with the surety companies a fee for the required surety bond. Firms bid. The firm with the lowest bid is awarded the project at the second lowest price. $^{14}$

3. The winning firm is simultaneously paid by the sponsor, signs the contract with the surety company, pays the fee and posts the surety bond. ${ }^{15}$

4. The firm starts constructing the project and finds out the true costs.

5. The firm finishes the project on its own or assisted by the surety company, or, alternatively, the surety pays the bond to the sponsor, who then finishes the project.

We now derive the equilibrium bids of the firm and the interest rate of the bond $r_{i}$ for each type of firm, for a given surety bond of size $L$ and a given financial value of the firm $A_{i}$. We derive these variables using the two zero profit conditions mentioned above:

\footnotetext{
${ }^{14}$ Notice that the contract between the surety company and the firm does not include the bid price of the latter. However, this is not important because when setting the surety fee, the surety company can infer with perfect information the bid strategy of the firm.

${ }^{15}$ Notice that the winning firm is paid by the sponsor at the same time that it pays the fee to the surety. Therefore, given that surety companies are perfectly competitive and have full information about contractor's wealth, any winning firm, even those with zero intial assets, is capable of posting the bond and getting the contract. Otherwise, if the winning firm had to pay the fee to the surety from their initial assets, firms with few intial assets would be denied the bond and would not be able to get the contract. However, in this alternative setup all results and intuitions would remain, except for the exclusion of firms with few initial assets.
} 
1. Since the procurement mechanism is a second price auction, the equilibrium bid has to leave the firm indifferent between winning or not winning the project.

$$
E\left\{\Pi_{i}\left(x_{i}=1, P_{i}^{*}, L, r_{i}\right)\right\}=A_{i} .
$$

2. Given perfect competition among surety companies, the surety has to be indifferent between issuing the surety bond or investing $L$ in a riskless asset:

$$
E\left\{\Pi_{S}\left(P, L, r_{i}\right)\right\}=r_{o} L
$$

where $E\left\{\Pi_{S}\left(P, L, r_{i}\right)\right\}$ denotes the expected profit of the surety company when it sells a surety bond to firm $i$ that is awarded the project at procurement price $P$ (which is the second lowest bid). Lemma 3 characterizes the equilibrium interest rate.

Lemma 3 The surety's interest rate $r_{i}$ is

1. a non-increasing function of firms' financial status $A_{i}$,

2. a non-increasing function of the size $L$ of the surety bond,

3. a non-decreasing function of $k_{B}$.

First, the worse the financial status of the firm, the higher the probability that the surety company will have to intervene helping the firm to finish the project. This implies that the surety company requires a higher interest rate from a firm with a worse financial status in order to compensate for the opportunity cost of the surety bond. Second, the bigger the surety bond $L$, the higher the cost of the surety bond for the firms and therefore the higher the firms' bid. A higher bid reduces the likelihood that the surety company has to pay the full surety bond, which implies that the interest rate decreases in the size of the surety bond. Finally, a higher $k_{B}$ means that the underlying uncertainty of the project increases. This makes firms in a bad financial situation bid more aggressively since very high costs, i.e. the bad shock occurs and $k_{B}$ is high, leaves them indifferent due to their losses being limited. Therefore, the surety company needs to set a higher interest rate when $k_{B}$ is higher in order to induce firms to bid less aggressively. 
Next, we characterize how the bid varies with the financial status of the firms.

Lemma 4 With a surety bond of size $L$ we get the following equilibrium bid functions:

1. For $L<\frac{k_{R}}{1-q}$ we get:

$$
P^{*}\left(A_{i}, L\right)= \begin{cases}c-k_{G}+\frac{q}{1-q} A_{i}+\left(r_{0}+q\right) L & \text { if } 0 \leq A_{i}<k_{B}-(1-q) L \\ c+r_{0} L & \text { if } A_{i} \geq k_{B}-(1-q) L\end{cases}
$$

2. For $L \geq \frac{k_{B}}{1-q}$ we get $P^{*}\left(A_{i}, L\right)=c+r_{0} L$.

Given Lemma 4, we separate these two cases to proceed with the analysis.

Corollary 2 If the sponsor asks for a surety bond of size $L<\frac{k_{B}}{1-q}$,

1. the function $P^{*}\left(A_{i}\right)$ is a continuous and non-decreasing function.

2. the project is always finished if and only if the financial status of the winning firm is $A_{i} \geq$ $k_{B}-(1-q) L$.

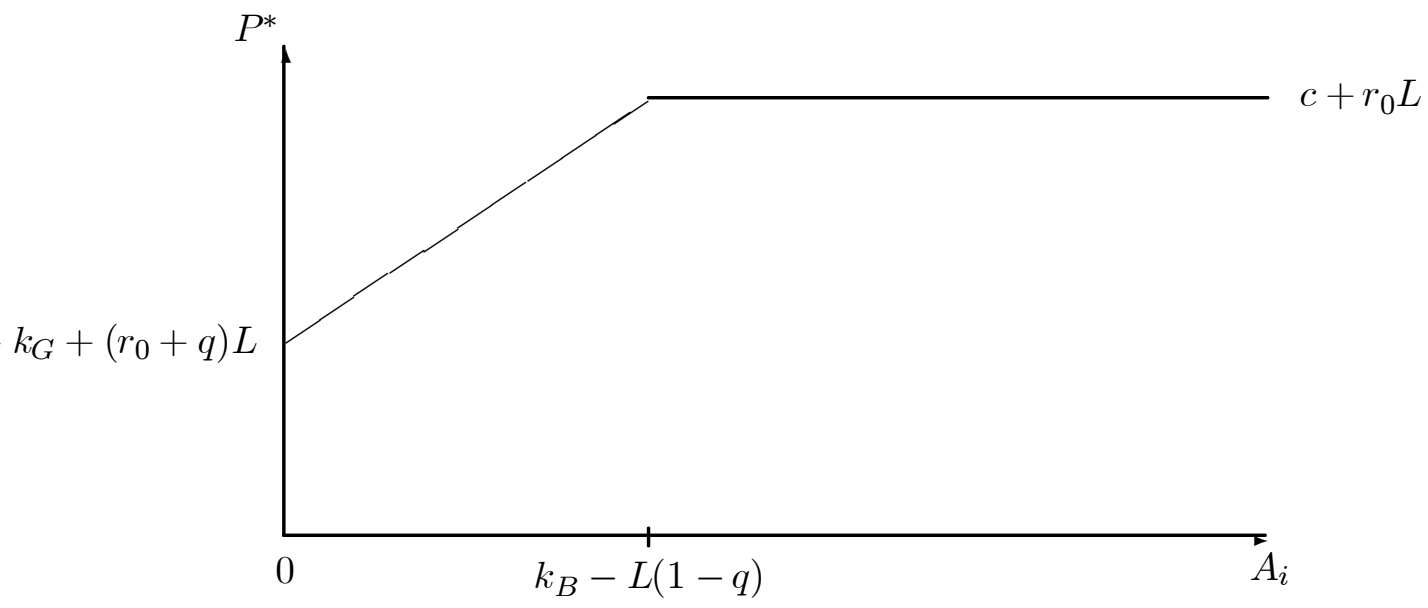

Figure 2: Bids as a function of the financial situation for $L<\frac{k_{B}}{1-q}$.

When the financial status of the firm $A_{i}$ lies in the interval $\left(k_{B}-(1-q) L, k_{B}\right)$ the project is always finished either by the firm alone or with the help of the surety, which implies that the bond $L$ is never paid to the sponsor. Notice also that in this interval the bid is the same as that 
of the completely solvent firm with $A_{i} \geq k_{B}$. To understand this result think of the firm and the surety as a coalition; the cash-flow accruing to this coalition is always the same for the range of $A_{i} \geq k_{B}-(1-q) L$ (since the bond is never paid to the sponsor). The difference between firms with $A_{i} \in\left(k_{B}-(1-q) L, k_{B}\right)$ and firms with $A_{i} \geq k_{B}$ is that in the latter group the surety never has to pay any money, whereas in the former the surety sometimes has to help the firm to finish the project. This is compensated by the fact that firms with $A_{i} \in\left(k_{B}-(1-q) L, k_{B}\right)$ pay a higher fee to the surety.

In figure 2 we see that any firm $A_{i} \in\left(0, k_{B}-(1-q) L\right)$ will bid more aggressively than a solvent firm. These firms might be unable to complete the project if they win the auction. With a bad shock, the surety prefers to pay $L$ to the sponsor instead of helping such a firm to finish the project. If there are $N$ firms, the probability that the winning firm lies in this "bankruptcy" interval is defined by

$$
\operatorname{prob}_{W}=1-\left[1-\left(F\left(k_{B}-(1-q) L\right)-F(0)\right)\right]^{N}
$$

where $F(\cdot)$ is the distribution function of firms. Clearly, the probability that the winning firm lies in the bankruptcy interval increases with the number of firms $N$, with the support of the bad shock $k_{B}$ and decreases in the size of the surety bond $L$. Compared to the situation without a surety bond $(L=0)$, the problem of abnormally low tenders is mitigated, but not eliminated. Now we will show that a large enough surety bond $L \geq \frac{k_{B}}{1-q}$ can eliminate completely the risk of bankruptcy for the sponsor and consequently the problem of abnormally low tenders.

Corollary 3 If the sponsor asks for a surety bond of size $L \geq \frac{k_{B}}{1-q}$,

1. the function $P^{*}\left(A_{i}\right)$ becomes a constant, independent of $A_{i}$.

2. the project is always finished.

This bid function is illustrated in Figure 3. The equilibrium bid for all firms with $A_{i} \geq 0$ is the same (for the same (analogous) reason as the equilibrium bid for all firms with $A_{i} \geq k_{B}-(1-q) L$ was the same in Corollary 2). Therefore, every firm has the same probability to win the auction. 


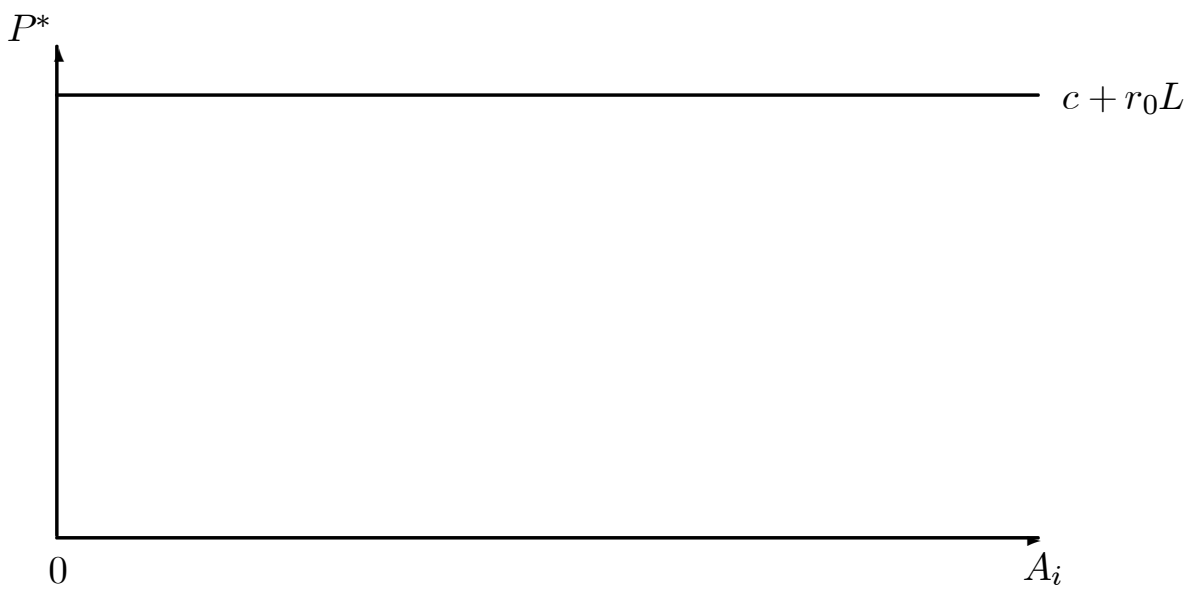

Figure 3: Bids as a function of the financial situation for $L \geq \frac{k_{B}}{1-q}$

Firms with $A_{i} \in\left[0, k_{B}\right)$ have to pay a higher fee for their surety bond than solvent firms, and might need the surety's help to finish the project. The project will always be finished, but the firm might end up with $\Pi_{i}=0$. Thus, when the size of the surety bond is larger than or equal to $\frac{k_{R}}{1-q}$ the project is always finished by the firm or the surety, and therefore the problem of abnormally low tenders disappear.

Finally, Proposition 2 summarizes the main results of this section.

Proposition 2 Requiring a surety bond reduces the problem of abnormally low tenders. If $L<$ $\frac{k_{B}}{1-q}$ the problem is mitigated but not eliminated, and if $L \geq \frac{k_{B}}{1-q}$ the problem of ALTs disappears.

\section{THE OPTIMAL SURETY BOND}

In this section we characterize the optimal surety bond for a sponsor who requires the same surety bond from all bidders. Lemma 5 places an upper bound on the size of the optimal surety bond.

Lemma 5 The optimal size of the surety bond $L^{*}$ is never larger than $\frac{k_{B}}{1-q}$.

For any $L \geq \frac{k_{R}}{1-q}$ the project is always finished (Proposition 2). Setting a size of the surety bond strictly larger than $\frac{k_{B}}{1-q}$ only increases the bid price. Therefore, the optimal surety bond must lie within the interval $\left[0, \frac{k_{B}}{1-q}\right]$. 
Let $A_{1}$ be the financial status of the winning firm, and let $A_{2}$ be the financial status of the firm that determines the procurement price (second lowest bid). The optimization problem of the sponsor is:

$$
\begin{aligned}
& \max _{L \in\left[0, \frac{k_{B}}{1-q}\right]} V-\int_{\substack{k_{B}-(1-q) L \\
k_{B}-(1-q) L}}^{\infty}\left[c+r_{0} L\right] f_{1}\left(A_{1}\right) d A_{1} \\
& -(1-q) \int_{0}^{k_{B}-(1-q) L}\left[\int_{A_{1}}^{k_{B}-(1-q) L}\left[c+\frac{q}{1-q} A_{2}-k_{G}+\left(r_{0}+q\right) L\right] f_{2}\left(A_{2}\right) d A_{2}\right] f_{1}\left(A_{1}\right) d A_{1} \\
& -(1-q) \int_{0}^{k_{B}}\left[\int_{k_{B}-(1-q) L}^{\infty}\left[c+r_{0} L\right] f_{2}\left(A_{2}\right) d A_{2}\right] f_{1}\left(A_{1}\right) d A_{1} \\
& -q \int_{0}^{k_{B}-(1-q) L}\left[c+k_{B}-\left(1-r_{0}-q\right) L-A_{1}+C_{B}\right] f_{1}\left(A_{1}\right) d A_{1}
\end{aligned}
$$

where $f_{1}\left(A_{1}\right)$ is the density function of the minimum $A_{i}$ and $f_{2}\left(A_{2}\right)$ is the density function of the second-lowest financial status.

The first integral represents the case when the project is always finished, i.e. $A_{1} \geq k_{B}-L(1-q)$, either because the winning firm is solvent or because the surety finishes the project in case of a bad shock. The other integrals capture the situations in which the project is finished if and only if the shock is good. The double integrals represent the case of a good shock, which occurs with probability $(1-q)$. In the first double integral the procurement price (the bid of the firm with the second lowest financial status $\left.A_{2}\right)$ is determined by another firm with $A_{2}<k_{B}-L(1-q)$. In the second double integral the procurement price is set by a firm without bankruptcy risk for the sponsor. Finally, the fourth integral captures the case in which the shock is bad and neither the insolvent firm nor the surety finish the project. The sponsor is then paid the bond and finishes the project on its own incurring in the bankruptcy costs. The expression (4) simplifies to:

$$
\begin{aligned}
& \max _{L \in\left[0, \frac{k_{B}}{1-q}\right]} V-\left[c+r_{0} L\right]-q \int_{0}^{k_{B}-(1-q) L}\left[k_{B}-(1-q) L-A_{1}+C_{B}\right] f_{1}\left(A_{1}\right) d A_{1} \\
& -(1-q) \int_{0}^{k_{B}-(1-q) L}\left[\int_{A_{1}}^{k_{B}-(1-q) L}\left[\frac{q}{1-q} A_{2}-k_{G}+q L\right] f_{2}\left(A_{2}\right) d A_{2}\right] f_{1}\left(A_{1}\right) d A_{1} .
\end{aligned}
$$


From the sponsor's optimization problem it follows immediately that that neither $c$ nor $V$ have any effect on the optimal size of the surety bond, a result that is stated in Lemma 6 .

Lemma 6 The optimal surety bond is independent of $c$ and $V$.

Despite the above simplification of the sponsor's optimization problem, it is difficult to find an analytical closed-form solution to it, and we present a numerical solution for the optimal surety bond. These numerical simulations allow us to provide some intuitions on how the optimal surety bond changes with the underlying parameters. We assume that the financial status of firms is distributed according to a uniform distribution over the interval $[0, b]$. The upper bound of this distribution can be regarded as an indicator of the solvency level of the industry. We also assume that $q=\frac{1}{2}$ and $k_{B}=k_{G}=k$. Given this parametrization, the problem is left with five parameters: the number of firms $n$, the size of the shock $k$, the riskless interest rate $r_{0}$, the cost of bankruptcy $C_{B}$, and $b$. The exercises are carried out by setting four of the parameters and allowing the other parameter to vary over a prespecified interval. ${ }^{16}$ We now show the graphs resulting from the simulations and discuss the intuitions behind them.

[Figure 4]

First, the more firms there are (i.e. the more draws there are from the distribution function of firms' assets), the lower is the financial status of the winning firm $A_{i}$ and the more likely it is that the winning firm will be insolvent. Therefore, the optimal surety bond should increase in the number of firms.

[Figure 5]

\footnotetext{
${ }^{16}$ The first exercise (that analyzes the relationship between the optimal surety bond and the number of firms) sets $b=20, r_{0}=0.2, k=3.5$ and $C_{B}=2.5$ and then computes the optimal surety bond for $n=\{2, \ldots, 10\}$. The second exercise (that studies the optimal surety bond as a function of the solvency level of the industry) sets $n=2$, $r_{0}=0.05, k=1$ and $C_{B}=0.75$, and computes the optimal surety bond when $b$ varies between 2 and 20 . Third, we compute the optimal surety bond as a function of the cost of bankruptcy $C_{B}$. We set $b=60, n=4, r_{0}=0.05$, $k=2.5$ and then vary $C_{B}$ between 1 and 3 . Fourth, we study the relationship between the optimal surety bond and the size of the shock $k$, by setting $b=60, n=4, r_{0}=0.05$ and $C_{B}=3$. We then compute the optimal surety bond when $k$ varies between 0.5 and 2.5. And finally, we compute the optimal surety bond as a function of the riskless interest rate $r_{0}$. We set $b=70, n=3, k=4$ and $C_{B}=4$ and then we compute the optimal surety bond when $r_{0}$ varies between 0.05 and 0.1 . Figures 4 through 8 plot the optimal surety bond obtained in the simulations as a function of the parameters under study.
} 
Second, if the distribution function of assets is such that it is more likely that the draws lead to a solvent winning firm (in the simulations this means an increase in the upper bound of the uniform distribution), then the optimal surety bond should decrease.

[Figure 6]

Third, when the cost of bankruptcy $C_{B}$ increases, the sponsor's incentives to reduce the risk of bankruptcy increases. Thus the sponsor optimally should require a higher surety bond.

\section{[Figure 7]}

Fourth, if the size of the shock $k$ increases, more assets are required to eliminate all bankruptcy risk for the sponsor (both because there are more firms that can go bankrupt, and because the ones that go bankrupt do it by a larger amount). Hence, the optimal surety bond should increase.

\section{[Figure 8]}

And last, a higher $r_{0}$ increases the cost of the surety and increases the procurement price, with the implication that the risk of bankruptcy is reduced, which implies that the optimal surety bond should decrease with the riskless interest rate.

To summarize, according to the simulations the size of the optimal bond should increase in the underlying uncertainty of the project (the size of the shock); in the number of potentially bidding firms, and in bankruptcy costs. It should be decreasing in the solvency level of the industry, and in the riskless interest rate.

\subsection{The US practice}

In the US public construction projects that exceed $\$ 100,000$ are regulated by the Miller Act. The Miller Act requires that the firm which is awarded the project purchases a performance bond. The required performance bond (which guarantees the quality and completion time of the project) 
is usually $100 \%$ of the contract price. ${ }^{17}$ Now we assess this requirement in our model, by assuming that the sponsor requests the winning firm to post a surety bond equal to its contract price, that is, it requests $L=P$.

Lemma 7 Requiring a surety bond equal to the contract price (i.e., $L=P$ ), will lead to a surety bond in equilibrium of

$$
\begin{aligned}
\text { (i) } L & =\frac{c}{1-r_{0}} \text { if } k_{B} \leq \frac{1-q}{1-r_{0}} c, \\
\text { (ii) } L & =\left\{\begin{array}{ll}
\frac{c}{1-r_{0}} & \text { if } k_{B}>\frac{1-q}{1-r_{0}} c \text { and } A_{2} \geq k_{B}-\frac{1-q}{1-r_{0}} c \\
\frac{c-k_{G}+\frac{q_{2}}{1-q}}{1-r_{0}-q} & \text { if } k_{B}>\frac{1-q}{1-r_{0}} c \text { and } 0 \leq A_{2}<k_{B}-\frac{1-q}{1-r_{0}} c
\end{array} .\right.
\end{aligned}
$$

Recall that the firm with the second lowest financial status has $A_{2}$ assets, and its bid determines the procurement price. From Lemma 7 it is clear that with the US practice the size of the surety bond depends positively on the cost of the project and also positively on the riskless interest rate. In contrast, from section 4 we know that the optimal surety bond does not depend on the expected cost of the project $c$, and decreases in the riskless interest rate. Therefore, the US practice of requiring $L=P$ implies a surety bond that does not react to changes in some of the parameters in an optimal manner. In particular this implies overinsurance when the bad shock and/or its probability $q$ is not too large.

Corollary 4 When $k_{B} \leq \frac{1-q}{1-r_{0}}$ c, requiring a surety bond equal to the contract price (i.e., $L=P$ ) may provide overinsurance to the sponsor.

When $k_{B} \leq \frac{1-q}{1-r_{0}} c$, the equilibrium surety bond is $\frac{c}{1-r_{0}}>\frac{k_{B}}{1-q}$, which is the size of the smallest surety bond that eliminates all risk of bankruptcy. Thus, a smaller surety bond would also eliminate the risk of bankruptcy for the sponsor at a lower procurement price. The driving force behind this result is that when $L=P$ the size of the surety bond is linked to the expected cost of the project, but not to the underlying uncertainty of the project. Thus, with the US practice two projects with the same expected cost but different underlying uncertainty will be covered by

\footnotetext{
${ }^{17}$ Besides the performance bond there is a payment bond (which ensures the payment of the subcontractors and workers) which sometimes equals the amount of the performance bond. Hence, surety bonds in the US ensure well over $100 \%$ of the contract price.
} 
surety bonds of the same size. However, following the characterization of the optimal surety bond in Section 4, we know that a project with a small bad shock requires a small surety bond since the number of firms that can go bankrupt is also small. The US practice however, only links the size of the surety bond to the expected $\operatorname{cost} c$, leading to the overinsurance result.

\section{Other REgUlatory MEASURES}

Surety bonds are used in the US, Canada and Japan, but are not common in Europe. In this section we briefly discuss other practical attempts to deal with the problem of abnormally low tenders.

\subsection{Letters of credits}

It is sometimes suggested that letters of credits could serve a similar purpose to surety bonds. After all, both systems guarantee that the sponsor will receive at least a certain amount of money, $L$, should bankruptcy occur. However, letters of credits differ fundamentally from surety bonds in their nature and in the incentives they provide. To issue a letter of credit, banks require from the contractor to pledge specific assets; these assets are paid to the sponsor should the letter, which is not tied to the underlying contract, be called. Hence, banks take no risk at all and therefore have no incentive to screen firms, whose liquidity is reduced since some of their assets are frozen to back up the letter of credit. In contrast, surety bonds do not alter firms' assets; some risk is shifted to the surety company who helps the firm to finish the project should this require less resources from the surety than the payment of the surety bond. Surety companies therefore heavily screen firms before issuing the bond. Given these major differences, it is not surprising that letters of credits cannot serve the same purpose as surety bonds. While letters of credits exclude firms with financial status $A_{i}<L$ from participating in the auction, they aggravate the danger of bankruptcy of participating firms.

To see this point notice that with no policy intervention any firm with $A_{i} \geq k_{B}$ is solvent in 
the sense that it will never go bankrupt (Corollary 1). With letters of credits only "supersolvent" firms with $A_{i} \geq k_{B}+L$ (who only have access to $A_{i}-L$ of their assets during the construction process since the amount $L$ is frozen) are immune to bankruptcy. By worsening their financial situation, letters of credits convert some good firms, namely $A_{i} \in\left(k_{B}, k_{B}+L\right)$, into insolvent firms. ${ }^{18}$

\subsection{Detection by deviations from average price}

A common system to face the problem of abnormally low tenders is to exclude those tenders from the procurement process whose bids differ by more than a certain percentage (e.g.10\% or $15 \%$ ) from the average of tender bids or from the second lowest bid. ${ }^{19}$ However, an endogenous threshold cannot be an effective screening device, since insolvent firms can always increase their bids to mimic the behavior of firms in a good financial status. This strategic reaction of firms to the endogenous threshold is very likely to result in the inexistence of pure strategy equilibria in which those firms with a bad financial status are excluded from winning the auction. ${ }^{20}$ Consequently, it seems likely that the endogenous threshold will fail to serve its purpose. ${ }^{21,22}$

\section{Conclusion}

Some public managers point out that it is very risky to use auctions in public procurement, especially for small or medium-sized projects where the market of potential contractors is very big and little is known about individual firms. They claim that the winner of the auction can be a firm

\footnotetext{
${ }^{18}$ For a formal analysis of letters of credit and the resulting equilibrium bids see the working paper of a previous version of the present article (Calveras et al. (2001)).

${ }^{19}$ This system is used e.g. in Belgium, Greece, Italy and Spain and is under discussion in France.

${ }^{20}$ The working paper of a previous version of this article Calveras et al. (2001) proves this result for the special case of a first price auction with perfect information among firms.

${ }^{21}$ In fact, the report elaborated by a working group on the Prevention, Detection and Elimination of Abnormally Low Tenders in the European Construction Industry points out that there is no information at all concerning the efficiency of this system.

${ }^{22}$ Another weak point of using an endogenous threshold is that it might induce collusion among the firms. One way in which a cartel can avoid competition is by increasing their bids by common agreement in order to disqualify non cartel members as abnormally low bidders. Since collusion is costly for the sponsor, any device that facilitates collusion should be avoided.
} 
with a high probability of bankruptcy. In this paper we show that this fear is realistic. Since firms are protected by limited liability when they declare bankruptcy, firms in a bad financial situation have little to lose but a lot to win and therefore bid very aggressively in the procurement process. It is therefore likely that the winning firm is a firm in financial difficulties. This problem, which is known as abnormally low tenders, makes it necessary to modify the selection mechanism.

In this paper we have focused on the regulatory measure of requiring surety bonds, which seems to be the most effective system used in practice. Surety bonds serve as a screening device in the procurement auction: by increasing the bids of insolvent firms, they reduce the bankruptcy risk for the sponsor. We have provided a numerical characterization of the optimal surety bond, with the result that it should not depend on the expected cost of the project; should be increasing in the number of potential contractors, the support of the underlying uncertainty of the project, the bankruptcy costs; and decreasing in the level of solvency of the industry and the riskless interest rate.

Our model shows that surety bonds as used in the US are indeed effective in eliminating ALTs. However, when either the bad shock or its probability is not too large, our model predicts that the US practice of requiring the bond to cover over 100 per cent of the contract price provides overinsurance to the problem of ALTs. This is because, in contradiction with what should be the optimal bond, the US practice links the size of the surety bond to the expected cost of the project and not to the underlying uncertainty, which is the ultimate cause of abnormally low tenders. It might be in general difficult to get precise estimators of the value of the uncertainty of the project and consequently it could be difficult to implement the optimal surety bond. However, it seems sensible to assume that the sponsor should be able to make a broad classification of the projects according with their uncertainty, and therefore requiring lower bonds to less risky projects. For example, when requiring a surety bond the sponsor should distinguish between a construction project that has been undertaken before many times (e.g. a local road) and a construction project for which there is little historical experience and therefore has higher underlying uncertainty (e.g. the tunnel between France and England). 


\section{A APPENDix}

\section{Proof of Lemma 1 and Corollary 1}

The equilibrium bid is determined by $E\left\{\Pi_{i}\left(x_{i}=1, P_{i}^{*}\right)\right\}=A_{i}$. There are two types of firms: (i) those that always finish the project and (ii) those that go bankrupt in case of a bad shock.

(i) Setting $E\left\{\Pi_{i}\left(x_{i}=1, P_{i}^{*}\right)\right\}=A_{i}$ implies $(1-q)\left[P_{i}^{*}-c+k_{G}+A_{i}\right]+q\left[P_{i}^{*}-c-k_{B}+A_{i}\right]=$ $A_{i}$. Straightforward calculations show that a firm that never goes bankrupt will always bid $P_{i}^{*}=c$, since the expected cost shock is zero. It remains to determine which firms never go bankrupt. Those are the firms that are able to finish the project even if the shock is bad. That is, $P_{i}^{*}-c-k_{B}+A_{i} \geq 0$, which implies $A_{i} \geq k_{B}$.

(ii) The bid function of a firm that goes bankrupt in case the shock is bad is determined by $E\left\{\Pi_{i}\left(x_{i}=1, P_{i}^{*}\right)\right\}=(1-q)\left[P_{i}^{*}-c+k_{G}+A_{i}\right]=A_{i}$ which implies an equilibrium bid of $P_{i}^{*}=c-k_{G}+\frac{q}{1-q} A_{i}$. It is easy to see that for $A_{i}<k_{B}$, this bid $c-k_{G}+\frac{q}{1-q} A_{i}<c$. Hence, $c$ is also the maximum possible procurement price. From (i) we know that firms with $A_{i}<k_{B}$ will not be able to finish the project if the shock is bad even at the maximum possible procurement price. Therefore, they will always declare bankruptcy when the shock is bad.

\section{Proof of Proposition 1}

Given the bid function it is immediate to see that when there is some firm with $A_{i} \in\left[0, k_{B}\right)$, the winning firm will not be a solvent firm.

\section{Proof of Lemma 2}

With full information the sponsor pays each firm its opportunity cost of contracting the project. This opportunty cost coincides with the firm's bid in the second price auction. If the firm awarded the contract is solvent, i.e. $A_{i} \geq k_{B}$, there is no bankruptcy risk; the sponsor's expected utility is then $U_{S}\left(A_{i} \geq k_{B}\right)=V-P=V-c$. If, on the other hand, the firm awarded the contract is not solvent, i.e. $A_{i}<k_{B}$, the sponsor has to bear the bankruptcy costs if the shock is bad. Therefore, expected utility of the sponsor is $U_{S}\left(A_{i}<k_{B}\right)=V-q\left[c+k_{B}-A_{i}+C_{B}\right]-(1-q)\left[c-k_{G}+\frac{q}{1-q} A_{i}\right]=$ $V-c-q C_{B}$. Thus, it is obtained that $U_{S}\left(A_{i} \geq k_{B}\right)>U_{S}\left(A_{i}<k_{B}\right)$ for positive bankruptcy 
costs.

\section{Proof of Lemma 3 and Lemma 4}

In this proof we will use equations (2) and (3) to characterize the equilibrium bids and the surety fees. We will have to distinguish several cases: firms that always finish the project on their own, without the assistance of the surety (case 1) and firms who finish the project if the shock is good but do not finish it if the shock is bad. In this latter case, two things might happen in case of a bad shock. Either the surety finishes the project (case 2) or it pays the surety bond to the sponsor (case 3). Notice that we cannot have firms that never finish the project on their own, since those firms have expected profits of zero, but $A_{i} \geq 0$ and by equation (2) firms' expected profit has to equal their initial assets.

1. Firms that always finish the project. In this case the surety sets $r=r_{0}$ (zero-profit condition). By equation (2) firms bid $P_{i}^{*}$ such that

$$
(1-q)\left[P_{i}^{*}-c+k_{G}+A_{i}-r_{0} L\right]+q\left[P_{i}^{*}-c-k_{B}+A_{i}-r_{0} L\right]=A_{i} .
$$

Hence the equilibrium bid is

$$
P_{i}^{*}=c+r_{0} L
$$

Take this bid $c+r_{0} L$ as the maximum bid, which implies it is the maximum procurement price that will be paid whatever firms are in the bidding process. (For the moment this is an assumption; at the end of the proof we will show it is indeed true.) It remains to be determined which firms will always finish the project. Firms need to have sufficient assets, when the shock is bad, namely

$$
P-c-k_{B}+A_{i}-r_{0} L \geq 0
$$

where $P$ is the procurement price, which in this case is the maximum bid $P_{i}^{*}=c+r_{0} L$. Hence, these are the firms with

$$
A_{i} \geq k_{B}
$$


2. Firms that finish the project if the shock is good, but the surety finishes the project if the shock is bad. In this case, using equation (3), the surety will set fees $r_{i}$ such that

$$
r_{i} L+q\left[P-c-k_{B}+A_{i}-r_{i} L\right]=r_{0} L .
$$

This implies that

$$
r_{i}=\frac{r_{0}}{1-q}-q \frac{P-c-k_{B}+A_{i}}{L(1-q)}
$$

Equation (2) determines firms' bid, namely

$$
(1-q)\left[P_{i}^{*}-c+k_{G}+A_{i}-r_{i} L\right]=A_{i}
$$

since firms will lose all their assets if the shock is bad. Substituting (5) into this expression and simplifying we get

$$
(1-q) P_{i}^{*}+q P=c+r_{0} L
$$

Notice that the right-hand side of the equation is equal to the bid of those firms that always finish the project, while the left-hand side is a weighted average of the true procurement price and the bid of those firms whom the surety helps to finish the project if the shock is bad. Therefore, given the characteristics of a second price auction we must have

$$
P_{i}^{*}=P=c+r_{0} L
$$

since, as we assumed above, $c+r_{0} L$ is the maximum procurement price.

It remains to determine the assets of the firms for which the surety prefers to finish the project to paying the surety bond, namely $P-c-k_{B}+A_{i}-r_{i} L \geq-L$. Substituting the surety fee $r_{i} L$ and reformulating, we obtain

$$
A_{i} \geq k_{B}-(1-q) L
$$

This condition captures all firms with $A_{i}<k_{B}$, if the right-hand side is negative, which requires

$$
L \geq \frac{k_{B}}{1-q}
$$


3. Firms that finish the project if the shock is good, and the surety pays the surety bond if the shock is bad. In this case, the surety's zero-profit condition is

$$
r_{i} L-q L=r_{0} L .
$$

Hence the surety fee will be

$$
r_{i}=r_{0}+q,
$$

which is independent of the procurement price. Firms' bid function is determined by

$$
(1-q)\left[P_{i}^{*}-c+k_{G}+A_{i}-r_{i} L\right]=A_{i}
$$

Introducing (6) and rearranging we get the following bid:

$$
P_{i}^{*}=c-k_{G}+\frac{q}{1-q} A_{i}+\left(r_{0}+q\right) L
$$

It remains to determine the assets of the firms for which the surety prefers to pay the surety bond to finishing the project, namely $P-c-k_{B}+A_{i}-r_{i} L<-L$. Substituting the fee set by the surety and the maximum possible procurement price (since this is the best possible scenario for the surety for finishing the project), we obtain

$$
A_{i}<k_{B}-(1-q) L
$$

Notice that it is thus possible to be in this third case if the right-hand side is positive, which requires

$$
L<\frac{k_{B}}{1-q}
$$

Finally notice that firms' bid function in this case (3) is smaller than, and converges from below to, the maximum procurement price $c+r_{0} L$ when $A_{i}$ tends to $k_{B}-(1-q) L$.

Finally, it is left to show the assumption we made above that $c+r_{0} L$ is the maximum procurement price. It is immediate given expression $(1-q) P_{i}^{*}+q P=c+r_{0} L$ in case (2) and given we showed that the bid $c-k_{G}+\frac{q}{1-q} A_{i}+\left(r_{0}+q\right) L$ in case (3) is smaller than $c+r_{0} L$ (for the relevant financial status of the firms). 
To summarize, there are two situations. First, when $L \geq \frac{k_{B}}{1-q}$, then all firms bid $c+r_{0} L$, and the surety fee is $r_{0}$ for firms with $A_{i} \geq k_{B}$, and $r_{0}+\frac{q\left[k_{B}-A_{i}\right]}{L(1-q)}$ for firms with $A_{i}<k_{B}$.

And second, when $L<\frac{k_{B}}{1-q}$, then firms with $A_{i} \geq k_{B}$ bid $c+r_{0} L$ and pay a surety fee $r_{0}$; firms with $A_{i} \in\left(k_{B}-(1-q) L, k_{B}\right)$ also bid $c+r_{0} L$ and pay a surety fee $r_{0}+\frac{q\left[k_{B}-A_{i}\right]}{L(1-q)} ;$ and firms with $A_{i}<k_{B}-(1-q) L$ bid $c-k_{G}+\frac{q}{1-q} A_{i}+\left(r_{0}+q\right) L$ and pay a surety fee of $r_{0}+q$.

To conclude, we show in which way the interest rate depends on $A_{i}, L$ and $k_{B}$.

First, for $L<\frac{k_{B}}{1-q}$ :

$\frac{\partial r\left(A_{i}, L\right)}{\partial A_{i}}= \begin{cases}0 & \text { if } 0 \leq A_{i}<k_{B}-(1-q) L, \\ -\frac{q}{L(1-q)}<0 & \text { if } k_{B}-(1-q) L \leq A_{i}<k_{B}, \\ 0 & \text { if } A_{i} \geq k_{B} .\end{cases}$

For $L \geq \frac{k_{R}}{1-q}$ :

$\frac{\partial r\left(A_{i}, L\right)}{\partial A_{i}}= \begin{cases}-\frac{q}{L(1-q)}<0 & \text { if } 0 \leq A_{i}<k_{B}, \\ 0 & \text { if } A_{i} \geq k_{B} .\end{cases}$

Second, it is immediate to see that $r\left(A_{i}, L\right)$ is decreasing in $L$, and third, it is immediate to see that $r\left(A_{i}, L\right)$ is increasing in $k_{B}$.

\section{Proof of Corollary 2}

1. Immediate from calculating

$$
\frac{\partial P^{*}\left(A_{i}\right)}{\partial A_{i}}= \begin{cases}\frac{q}{1-q}>0 & \text { if } 0 \leq A_{i}<k_{B}-(1-q) L, \\ 0 & \text { if } A_{i} \geq k_{B}-(1-q) L .\end{cases}
$$

2. Immediate from the proofs of Lemma 3 and Lemma 4 .

\section{Proof of Corollary 3}

1. Immediate from calculating $\frac{\partial P^{*}\left(A_{i}\right)}{\partial A_{i}}=0$

2. Immediate from the proofs of Lemma 3 and Lemma 4 .

\section{Proof of Proposition 2}

Immediate from previous Lemmas and Corollaries.

\section{Proof of Lemma 5}

Immediate from Proposition 2.

\section{Proof of Lemma 6}


Immediate from the optimization problem of the sponsor.

\section{Proof of Lemma 7}

First, take the case when the surety bond is larger than $\frac{k_{B}}{1-q}$. In such a case, all firms bid the same, namely the maximum procurement price $c+r_{o} L$. Then, requiring a surety bond equal to the procurement price $(L=P)$ implies

$$
L=c+r_{o} L
$$

Hence,

$$
L=\frac{c}{1-r_{0}}
$$

We have to check whether this $L$ is indeed high enough, i.e. $\frac{c}{1-r_{0}} \geq \frac{k_{B}}{1-q}$, that is,

$$
c \geq \frac{1-r_{0}}{1-q} k_{B}
$$

If condition (7) holds, then we are done.

If condition (7) does not hold, we are in the case where $L<\frac{k_{B}}{1-q}$. Then, if the financial state of the winning firm is $A_{i} \geq k_{B}-(1-q) L$, the surety firm will finish the project in case of a bad shock, and we know from the proof of lemma 3 that in this case, the procurement price is also the maximum maximum procurement price $c+r_{o} L$. Then, using as before $L=P$, we obtain $L=\frac{c}{1-r_{0}}$, and by substituting it into the previous condition on the financial state of the winning firm we obtain it is equivalent to

$$
A_{i} \geq k_{B}-\frac{1-q}{1-r_{0}} c
$$

If, on the other hand, the financial state of the winning firm is $A_{i}<k_{B}-(1-q) L$, then the procurement price is determined by the second lowest bid. Let $A_{2}$ be the financial status of the firm with the second lowest bid. If $A_{2} \geq k_{B}-\frac{1-q}{1-r_{0}} c$, this second lowest bid is also the maximum procurement price and therefore the procurement price is $P=L=\frac{c}{1-r_{0}}$ as before. If $A_{2}<k_{B}-\frac{1-q}{1-r_{0}} c$, then the procurement price is

$$
P=c-k_{G}+\frac{q}{1-q} A_{2}+\left(r_{0}+q\right) L
$$


which, by setting $L=P$, implies that

$$
L=\frac{c-k_{G}+\frac{q}{1-q} A_{2}}{1-r_{0}-q}
$$

It only remains to be shown that this $L=P>0$, since a negative procurement price does not make any sense. For the relevant $A_{2}$ to be $>0$, we need $c<\frac{1-r_{0}}{1-q} k_{B}$, which, by adding in one side of the inequality $(1-q) k_{G}-q k_{B}$, zero by assumption, and reformulating, is equivalent to

$$
c-k_{G}\left(2-r_{0}-q\right)<k_{B}\left(1-r_{0}-q\right) \text {. }
$$

Notice that the left-hand side $c-k_{G}\left(2-r_{0}-q\right)>c-c\left(2-r_{0}-q\right)=-c\left(1-r_{0}-q\right)$, since $c>k_{G}$. Therefore,

$$
c-c\left(1-r_{0}-q\right)<c-k_{G}\left(2-r_{0}-q\right)<k_{B}\left(1-r_{0}-q\right)
$$

which can only be satisfied if $1-r_{0}-q>0$, which is also the denominator of the surety bond. Hence $L=P>0$.

\section{Proof of Corollary 4}

From Lemma 7 we know that $L=\frac{c}{1-r_{0}}$ if condition (7) is satisfied and that this surety bond is bigger than $\frac{k_{R}}{1-q}$.

\section{REFERENCES}

Arvan, L. and Leite, A. (1990) "Cost overruns in long-term projects", International Journal of Industrial Organization 8(3), 443-467

Borden, R. (1998): Speech On Surety Bonding Presented Before AIE NECA. http://www.necanet.org/about/president/aiespeech.htm

Calveras, A., Ganuza, J. and Hauk, E. (2001). "Wild Bids. Gambling for Resurrection in Procurement Contracts", Working Paper, Universitat Pompeu Fabra.

Che, Y. and Gale, I. (1996). "Financial Constraints in Auctions: Effects and Antidotes.", Advances in Applied Microeconomics 6: 97-120 
Che, Y. and Gale, I. (1998). "Standard Auctions with Financially Constrained Bidders". Review of Economic Studies 65(1): 1-21

DG III Working Group on Abnormally Low Tenders (1999). "Prevention, Detection and Elimination of Abnormally Low Tenders in the European Construction Industry"

Donohue, D. and Thomas, G. (1996), "Surety Bond Basics", Construction Briefings, Federal Publications, Inc.

Ganuza J. (2000) "Competition and Cost Overruns. Optimal Misspecification of Procurement Contracts", Universitat Pompeu Fabra Working Paper 471.

Hansen, R.G. and Lott, J.R. (1991). "The Winner's Curse and Public Information in Common Value Auctions: a Comment", American Economic Review 81: 347-361

Kagel, J.H. and Levin, D. (1991) “The Winner's Curse and Public Information in Common Value Auctions: Reply" American Economic Review 81: 362-369

Klemperer, P. (1999). "Auction Theory: A Guide to the Literature". Journal of Economic Surveys. 13(3), 227-86.

Lewis, T. (1986) "Reputation and Contractual Performance in Long-term Projects", Rand Journal of Economics 17, 141-157

McMillan, J. Rothsschild, M. and Wilson, R. (1997). Introduction of Journal of Economics and Management Strategy 6: 425-430

Shleifer, A. and Vishney, R.W. (1997) "A Survey of Corporate Governance", Journal of Finance 52(2), $737-83$

Surety Information Office. http://www.sio.org/

Waehrer, K. (1995). "A Model of Auction Contracts with Liquidated Damages", Journal of Economic Theory 67: 531-555

Zheng, C. Z. (2001). "High Bids and Broke Winners", Journal of Economic Theory 100: 129-171 


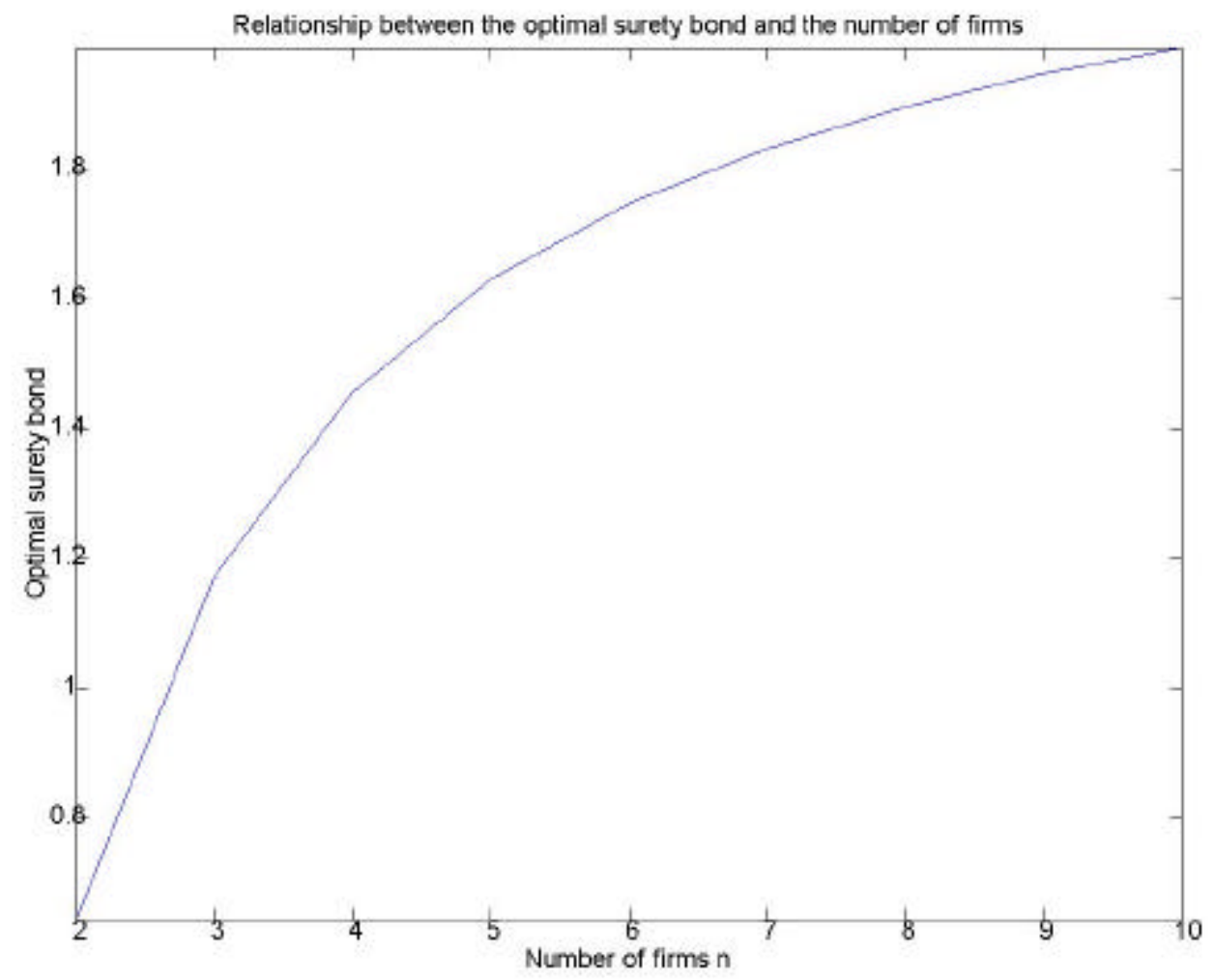

Figure 4.

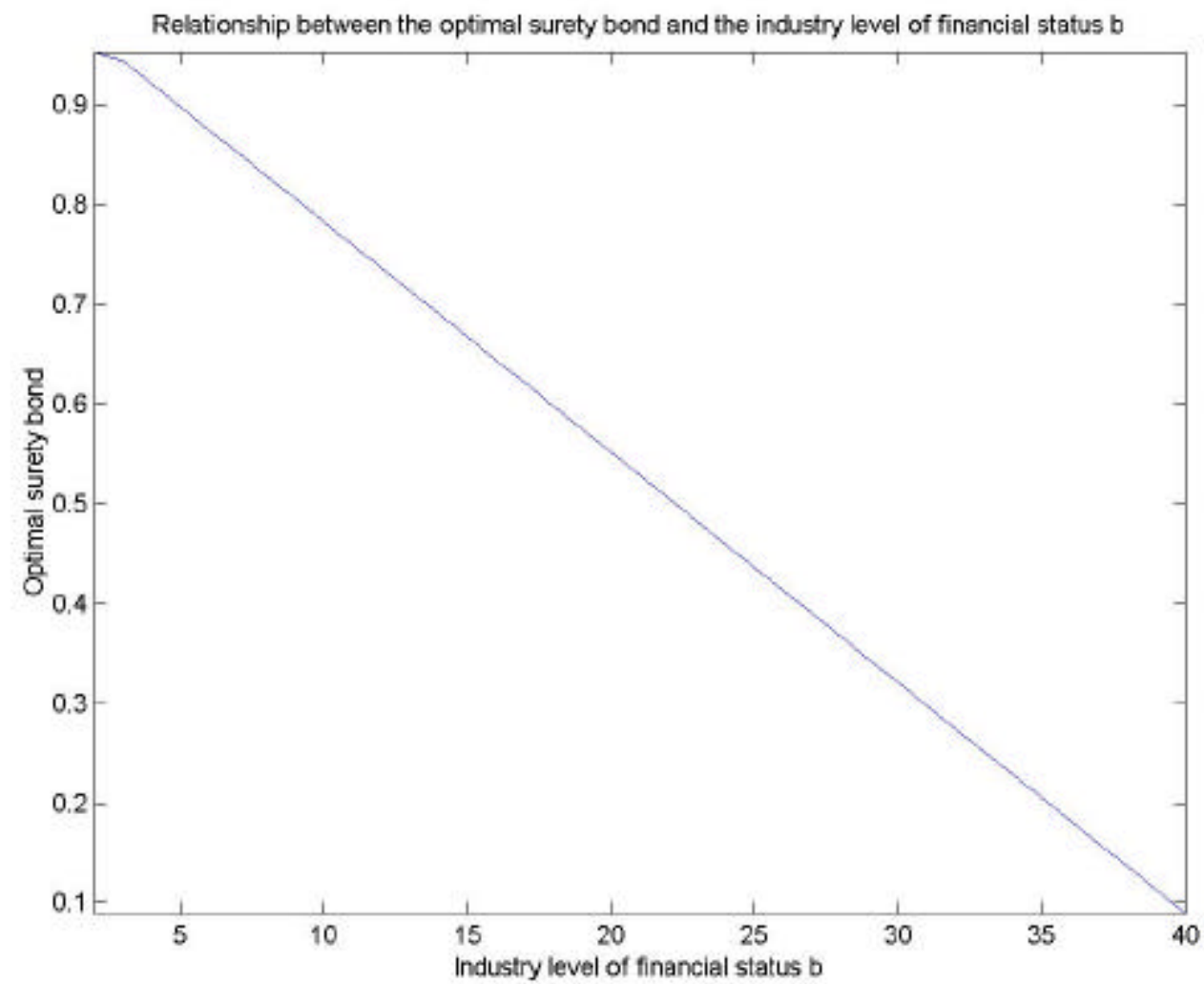

Figure 5. 


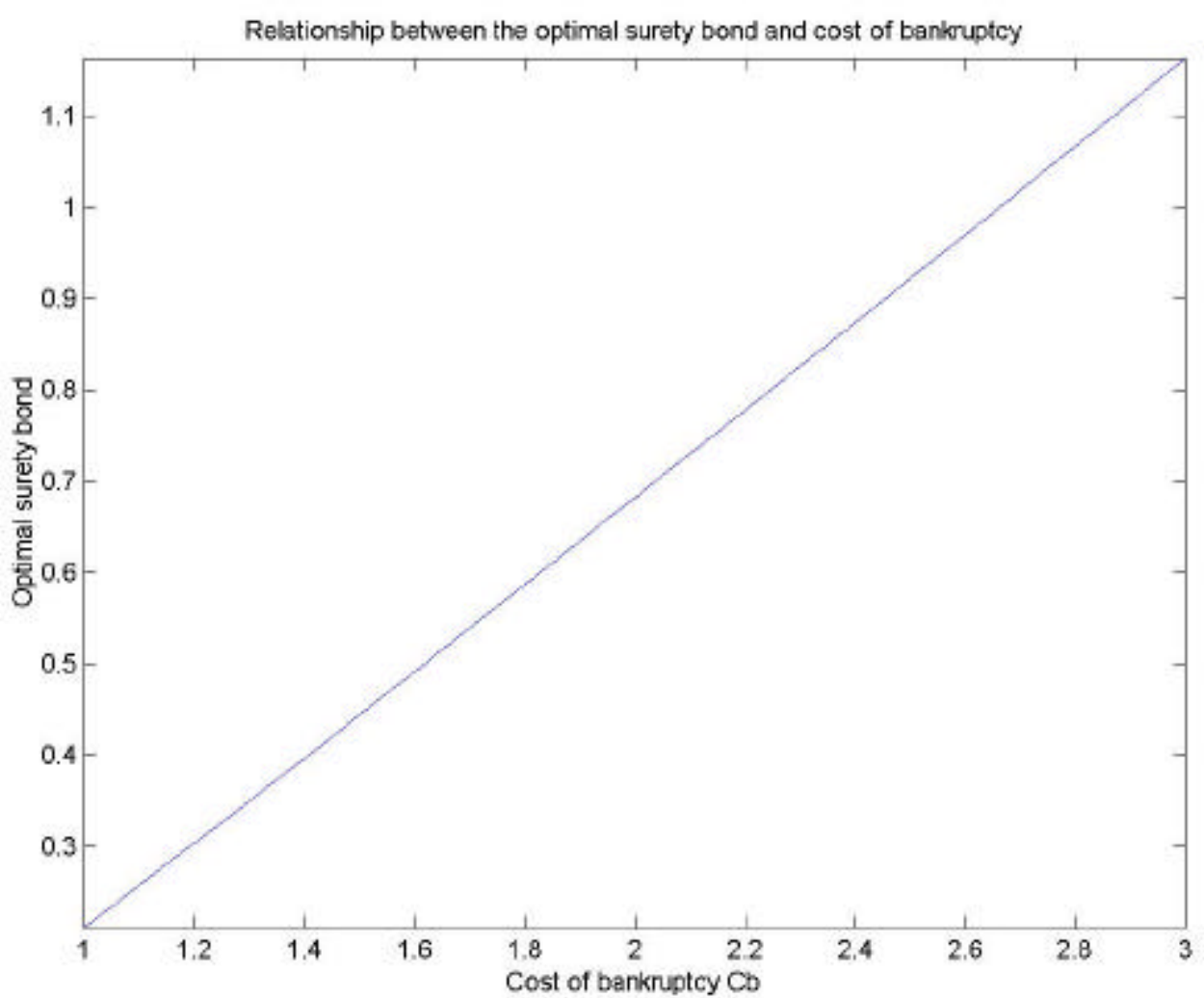

Figure 6.

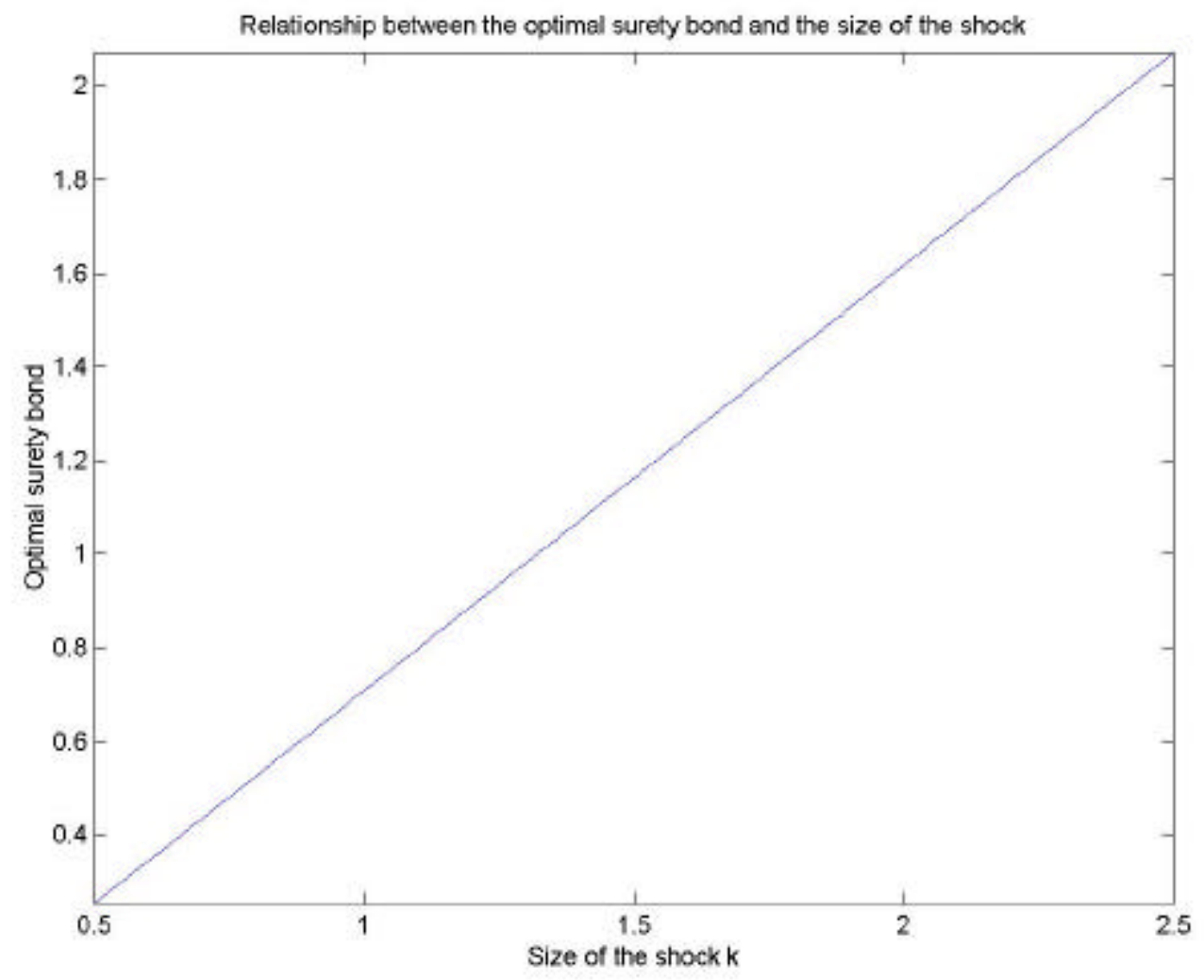

Figure 7. 


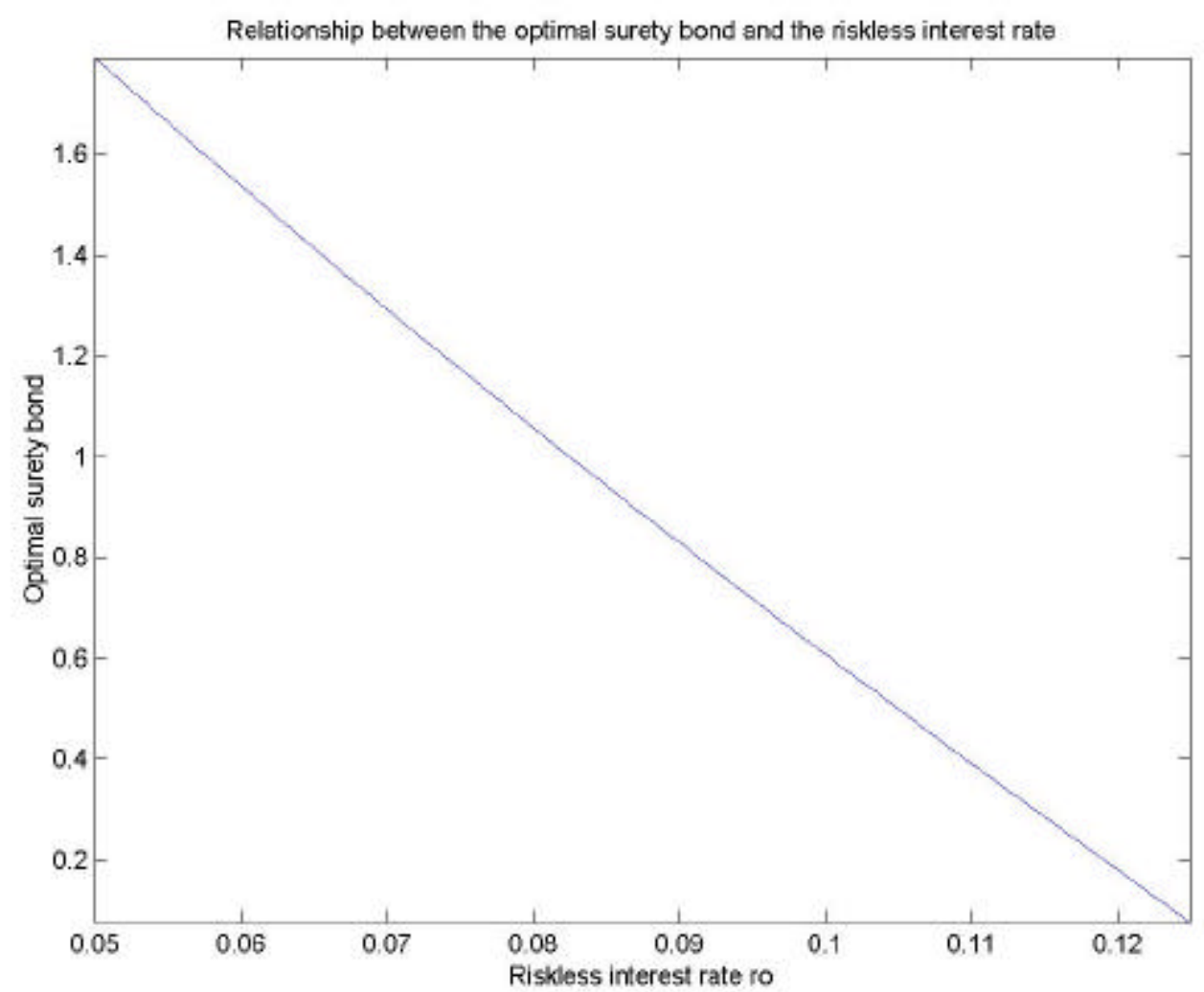

Figure 8 . 
Remark 1 In our setup the first price auction (FPA) and second price auction (SPA) yield the same expected outcome.

To prove this result we will take as a starting point that the FPA has a symmetric equilibrium which is characterized by a bid function that depends on the financial status $A_{i}$ of the firms, namely $b_{F}\left(A_{i}\right)$. Lemma 2 characterizes the feasible bids.

Lemma $2 b_{F}\left(A_{i}\right) \in\left[c-k_{G}, c\right]$

Proof. (i) On one hand, bids cannot be lower than $c-k_{G}$, because all firms independently of their $A_{i}$ would lose money if they won with such a bid: even in case of a good shock. (ii) On the other hand, all firms independently of their $A_{i}$ would win money in expected terms if they would win the auction with a bid higher than $c$. Hence, the firm with the lowest probability of winning could undercut this bid by $\varepsilon$, increasing its probability of winning and still maintaining positive profits. Competition among firms will reduce the bids to $c$. Hence, $b_{F}\left(A_{i}\right)>c$ cannot be part of the equilibrium bid function.

Lemma 3 All firms with $A_{i} \geq k_{B}$ can be treated as being of the same type (highest opportunity cost type), bidding $b_{F}\left(A_{i}\right)=c$ and making net benefit $\pi\left(b_{F}\left(A_{i}\right), A_{i}\right)=0$.

Proof. For contradiction assume that a firm with $A_{i} \geq k_{B}$ bids $b_{F}\left(A_{i}\right)<c$. If bankruptcy never occurs, $\pi\left(b_{F}\left(A_{i}\right), A_{i}\right)=b_{F}\left(A_{i}\right)-c<0$. If bankruptcy is possible, the firm will loose its assets in case of a bad shock and finish the project in case of a good shock. Hence, $\pi\left(b_{F}\left(A_{i}\right), A_{i}\right)=(1-q)\left(b_{F}\left(A_{i}\right)-c+k_{G}\right)-q A_{i} \leq$ $(1-q)\left(b_{F}\left(A_{i}\right)-c+k_{G}\right)-q k_{B}=(1-q)\left(b_{F}\left(A_{i}\right)-c\right)<0$. Hence $b_{F}\left(A_{i}\right)<c$ is impossible since the firm will loose money always. Therefore $b_{F}\left(A_{i}\right) \geq c$. In this case bankruptcy does not occur, hence $\pi\left(b_{F}\left(A_{i}\right), A_{i}\right)=b_{F}\left(A_{i}\right)-c$. But we know from Lemma 2 that the maximum possible bid is $c$. Hence, $b_{F}\left(A_{i}\right)=c$ for $A_{i} \geq k_{B}$ and $\pi\left(b_{F}\left(A_{i}\right), A_{i}\right)=0$. This net benefit function is independent of $A_{i}$. Therefore, we can treat all firms with $A_{i} \geq k_{B}$ as if they were a single type making zero net benefits and bidding $c$.

Lemma 3 shows that we can treat all firms with $A_{i} \geq k$ identically and work with them as if we had a mass point in the extreme of the interval $A_{i}=k$. Lemma 4 shows that the utility function is linear and continuous in $A_{i}=k_{B}$.

Lemma 4 Firms are risk neutral for all feasible bids.

Proof. By Lemma 3 we can treat all firms with $A_{i}>k_{B}$ as if they were $A_{i}=k_{B}$, bidding $b_{F}\left(A_{i}\right)=c$ and making net benefit $\pi\left(b_{F}\left(A_{i}\right), A_{i}\right)=0$. We have to show that for $A_{i}<k_{B}$ the utility function is linear and continuous in $A_{i}=k_{B}$. The net benefits for firms with $A_{i}<k_{B}$ if they win the auction are

$$
\pi\left(b_{F}\left(A_{i}\right), A_{i}\right)=(1-q)\left(b_{F}\left(A_{i}\right)-c+k_{G}\right)-q A_{i}
$$


since they will loose their assets if the shock is bad and increment their assets by the difference between the bid and the cost if the shock is good. Observe that for $A_{i}=k_{B}$ equation 1 becomes $\pi\left(b\left(k_{B}\right), k_{B}\right)=(1-q)\left(b\left(k_{B}\right)-c+k_{G}\right)-q k_{B}=$ $(1-q) k_{G}-q k_{B}=0$. Hence, the utility function is continuous in $A_{i}=k_{B}$ and equation 1 represents the utility of all firms with $A_{i} \in\left[0, k_{B}\right]$ and is clearly linear. Since all firms with $A_{i}>k_{B}$ are equivalent to $A_{i}=k_{B}$, this utility function characterizes all firms.

Lemma 5 shows that as in the SPA firms with less assets bid more aggressively in the FPA.

Lemma 5 In the first price auction $b^{\prime}\left(A_{i}\right)<0$ for $A_{i} \in\left[0, k_{B}\right]$

Proof. Assume without loss of generality that $A_{i}>A_{j}$. A condition for $b_{F}\left(A_{i}\right)$ to be an equilibrium is that nobody wants to deviate. Hence, the following condition has to be satisfied for firm $i$ :

$$
\pi\left(b_{F}\left(A_{i}\right), A_{i}\right) \rho\left(b_{F}\left(A_{i}\right)\right) \geq \pi\left(b\left(A_{j}\right), A_{i}\right) \rho\left(b\left(A_{j}\right)\right)
$$

$\left((1-q)\left(b_{F}\left(A_{i}\right)-c+k_{G}\right)-q A_{i}\right) \rho\left(b_{F}\left(A_{i}\right)\right) \geq\left((1-q)\left(b\left(A_{j}\right)-c+k_{G}\right)-q A_{i}\right) \rho\left(b\left(A_{j}\right)\right)$

where $\rho\left(b_{F}\left(A_{i}\right)\right)$ is the expected probability of winning the auction given $b_{F}\left(A_{i}\right)$. Given the rules of the first price auction, $\rho($.$) has to be non-decreasing. Similarly$ for firm $j$ we have:

$$
\begin{gathered}
\pi\left(b\left(A_{j}\right), A_{j}\right) \rho\left(b\left(A_{j}\right)\right) \geq \pi\left(b_{F}\left(A_{i}\right), A_{j}\right) \rho\left(b_{F}\left(A_{i}\right)\right) \\
\left((1-q)\left(b\left(A_{j}\right)-c+k_{G}\right)-q A_{j}\right) \rho\left(b\left(A_{j}\right)\right) \geq\left((1-q)\left(b_{F}\left(A_{i}\right)-c+k_{G}\right)-q A_{j}\right) \rho\left(b_{F}\left(A_{i}\right)\right)
\end{gathered}
$$

Adding up the two conditions and simplifying we obtain:

$$
\begin{gathered}
q\left(A_{i}-A_{j}\right) \rho\left(b\left(A_{j}\right)\right) \geq q\left(A_{i}-A_{j}\right) \rho\left(b\left(A_{j}\right)\right) \\
q\left(A_{i}-A_{j}\right)\left(\rho\left(b\left(A_{j}\right)\right)-\rho\left(b\left(A_{j}\right)\right)\right) \geq 0
\end{gathered}
$$

Since $A_{i}>A_{j}$ and $\rho($.$) is non-decreasing this condition implies that b\left(A_{j}\right) \geq$ $b_{F}\left(A_{i}\right)$.

Therefore the bid function has to be non-decreasing in the financial status of the firms. To show that it is strictly increasing in $A_{i}$, notice that if it were not, there would be an interval $\left[A^{\prime}, A^{\prime \prime}\right]$ in which all types would bid the same quantity, but then any bidder in this interval could deviate and increase his net benefits, by reducing infinitesimally his bid and increasing his probability of winning. 
By Lemma $2 b_{F}\left(A_{i}\right) \in\left[c-k_{G}, c\right]$, by Lemma 3 all firms with $A_{i} \geq k_{B}$ can be treated as being of the same type $k_{B}$ bidding $b_{F}\left(k_{B}\right)=c$ and making zero profits. Originally we assumed that $A_{i}$ is independently distributed on the interval $[0,+\infty)$ according to an arbitrary distribution function $F(\cdot)$. Given the above results, from now on we assume that $A_{i} \in\left[0, k_{B}\right]$, and that $A_{i}$ is distributed according to the distribution $G(A)$ which is identical to $F(\cdot)$ for $A<k_{B}$, and has a mass point on $k_{B}$ with density equal to $1-F\left(k_{B}\right)$.

The expected payment will be $x_{F}\left(A_{i}\right)=\rho_{F}\left(A_{i}\right) b_{F}\left(A_{i}\right)$. Hence, the expected profit of firm $i$ is: ${ }^{1}$

$$
\begin{gathered}
\pi_{F}^{E}\left(A_{i}\right)=\left[(1-q)\left(b_{F}\left(A_{i}\right)-c+k_{G}\right)-q A_{i}\right] \rho_{F}\left(A_{i}\right) \\
\pi_{F}^{E}\left(A_{i}\right)=(1-q) x_{F}\left(A_{i}\right)-\left[(1-q)\left(c-k_{G}\right)-q A_{i}\right] \rho_{F}\left(A_{i}\right)
\end{gathered}
$$

In the same way we write down the expected profits of a firm with a financial status of $A_{i}$ when the sponsor uses the SPA.

The expected payment will be $x_{S}\left(A_{i}\right)=\rho_{S}\left(A_{i}\right) E\left\{b_{S}\left(A_{2}\right) \mid A_{1}=A_{i}\right\}$. Therefore, the expected profit of firm $i$ is:

$$
\begin{gathered}
\pi_{S}^{E}\left(A_{i}\right)=\left[(1-q)\left(E\left\{b_{S}\left(A_{2}\right) \mid A_{1}=A_{i}\right\}-c+k_{G}\right)-q A_{i}\right] \rho_{S}\left(A_{i}\right) \\
\pi_{S}^{E}\left(A_{i}\right)=(1-q) x_{F}\left(A_{i}\right)-\left[(1-q)\left(c-k_{G}\right)+q A_{i}\right] \rho_{S}\left(A_{i}\right)
\end{gathered}
$$

Given that in a SPA and in a FPA the bidding functions are decreasing in $A_{i}$ the probability of winning is the same in both auctions, $\rho_{F}\left(A_{i}\right)=\rho_{S}\left(A_{i}\right)=\rho(s)$. Also, the expected profits of a firm with $A_{i}=k_{B}$ are zero, $\pi_{S}^{E}\left(k_{B}\right)=\pi_{F}^{E}\left(k_{B}\right)=$ $\rho\left(k_{B}\right)\left((1-q) c-(1-q)\left(c-k_{G}\right)-q k_{B}\right)=0$. Using these results, Lemma 6 shows that an arbitrary firm $i$ has the same expected profit in both auctions.

Lemma 6 The expected profit of firm $i$ in the FPA and in the SPA is the same, namely:

$$
\pi_{S}^{E}\left(A_{i}\right)=\pi_{F}^{E}\left(A_{i}\right)=q \int_{A_{i}}^{k_{B}} \rho(s) d s
$$

The equilibrium conditions of both auctions impose that $z=A_{i}$ will be the solution of the following incentive problem

$$
\max _{z}(1-q) x(z)-\left[(1-q)\left(c-k_{G}\right)+q A_{i}\right] \rho(z)
$$

\footnotetext{
${ }^{1}$ We have the standard private auction model with two differences: 1) By Lemma 4 the bidders' utility function is an affine transformation of the standard linear utility function. 2) A mass point in the extreme of the interval $\left(A_{i}=k\right)$. This mass point collects the bidders with the highest opportunity cost of constructing the project and therefore does not affect the differentiability of the distribution $H($.$) for the interior points, nor the incentives of the$ bidders since all bidders concentrated at the mass point get zero profits.
} 
Therefore, the first order condition of the problem imposes that

$$
(1-q) x^{\prime}\left(A_{i}\right)-\left[(1-q)\left(c-k_{G}\right)+q A_{i}\right] \rho^{\prime}\left(A_{i}\right)=0
$$

The expected profit of both auctions can be written as

$$
\pi_{S}^{E}\left(A_{i}\right)=\pi_{F}^{E}\left(A_{i}\right)=\pi^{E}\left(A_{i}\right)=(1-q) x\left(A_{i}\right)-\left[(1-q)\left(c-k_{G}\right)+q A_{i}\right] \rho\left(A_{i}\right)
$$

Deriving this function

$$
\pi^{E}\left(A_{i}\right)^{\prime}=(1-q) x^{\prime}\left(A_{i}\right)-q \rho\left(A_{i}\right)-\left[(1-q)\left(c-k_{G}\right)+q A_{i}\right] \rho^{\prime}\left(A_{i}\right)
$$

Using $(1-q) x^{\prime}\left(A_{i}\right)-\left[(1-q)\left(c-k_{G}\right)+q A_{i}\right] \rho^{\prime}\left(A_{i}\right)=0$, we can simply this expression to

$$
\pi^{E}\left(A_{i}\right)^{\prime}=-q \rho\left(A_{i}\right)
$$

Integrating now between $A_{i}$ and $k_{B}$

$$
\pi^{E}\left(k_{B}\right)-\pi^{E}\left(A_{i}\right)=-q \int_{A_{i}}^{k_{B}} \rho(s) d s
$$

Using that $\pi^{E}\left(k_{B}\right)=0$, we obtain

$$
\pi_{S}^{E}\left(A_{i}\right)=\pi_{F}^{E}\left(A_{i}\right)=q \int_{A_{i}}^{k_{B}} \rho(s) d s
$$

Given that the probability of winning $\rho_{F}\left(A_{i}\right)=\rho_{S}\left(A_{i}\right)$ and the expected profits $\pi_{S}^{E}\left(A_{i}\right)=\pi_{F}^{E}\left(A_{i}\right)$ of a firm with financial status $A_{i}$ are the same in the SPA and FPA, the expected payment to the contractor $i$ in both auctions is also the same.

$$
x^{E}\left(A_{i}\right)=x_{S}^{E}\left(A_{i}\right)=x_{F}^{E}\left(A_{i}\right)=\frac{q}{1-q} \int_{A_{i}}^{k_{B}} \rho(s) d s+\frac{(1-q)\left[c-k_{G}\right]+q A_{i}}{1-q} \rho\left(A_{i}\right)
$$

Using these results, we can now states that the expected outcome for the sponsor is the same in the FPA and in the SPA.

Lemma 7 The expected profits of the sponsor are the same in the first price auction (FPA) and in the second price auction (SPA), namely:

$$
U_{S}^{E}=U_{F}^{E}=V-c-q \int_{0}^{k_{B}}\left[\frac{G(A)}{g(A)}\right] h(A) d A-q C_{B}\left(1-\left[1-F\left(k_{B}\right)\right]^{N}\right)
$$

where $h(A)$ is the density function of the minimum of the sample $\left\{A_{1}, \ldots, A_{N}\right\}$ of $G(A)$ 
Dropping the subscripts, we compute the expected profit of the sponsor generated by an arbitrary contractor

$U_{S}=\int_{0}^{k_{B}}\left[V \rho(A)-(1-q) x(A)-q \rho(A)\left(c+k_{B}-A\right)-q \rho(A) C_{B} 1_{A<k_{B}}\right] g(A) d A$

Using the expresion of the expected payment, we obtain

$$
\begin{aligned}
& \int_{0}^{k_{B}}\left[V \rho(A)-q \int_{A_{i}}^{k_{B}} \rho(s) d s-(1-q)\left[c-k_{G}\right] \rho(A)-q A \rho(A)-q \rho(A)\left(c+k_{B}-A\right)\right. \\
& \left.-q \rho(A) C_{B} 1_{A<k_{B}}\right] g(A) d A
\end{aligned}
$$

This simplifies to

$$
\int_{0}^{k_{B}}\left[V \rho(A)-q \int_{A}^{k_{B}} \rho(s) d s-c \rho(A)-q \rho(A) C_{B} 1_{A<k_{B}}\right] g(A) d A
$$

Integrating by parts $\int_{0}^{k_{B}}\left(q \int_{A}^{k_{B}} \rho(s) d s\right) g(A) d A$ we obtain after some computations, $\int_{0}^{k_{B}}\left(q \rho(A) \frac{G(A)}{g(A)}\right) g(A) d A$. Then

$$
\int_{0}^{k_{B}}\left[V-c-q \frac{G(A)}{g(A)}-q C_{B} 1_{A<k_{B}}\right] \rho(A) g(A) d A
$$

Restoring the subscripts and summing over $i$ we obtain the sum of the sponsor's expected profits.

$$
\begin{gathered}
U_{S}=\sum_{i=1}^{N} \int_{0}^{k_{B}}\left[V-c-q \frac{G\left(A_{i}\right)}{g\left(A_{i}\right)}-q C_{B} 1_{A_{i}<k_{B}}\right] \rho\left(A_{i}\right) g\left(A_{i}\right) d A_{i} \\
U_{S}=V-c-q \int_{A_{1}} \ldots \int_{A_{N}} \sum_{i=1}^{N}\left[\frac{G\left(A_{i}\right)}{g\left(A_{i}\right)}+C_{B} 1_{A_{i}<k_{B}}\right] \quad(A) \prod_{i=1}^{N} g\left(A_{i}\right) d A_{i}
\end{gathered}
$$

In SPA and FPA ${ }_{i}(A)=1$ if and only if $A_{i} \in \arg \min \left\{A_{1}, \ldots, A_{N}\right\}$. We can assume also if $A_{1}=A_{2}=\ldots=A_{N}$, then any firm wins with probability $\frac{1}{N}$. Given this, the expected surplus of the sponsor is

$$
U_{S}^{E}=U_{F}^{E}=V-c-q \int_{0}^{k_{B}}\left[\frac{G(A)}{g(A)}\right] h(A) d A-q C_{B}\left(1-\left[1-F\left(k_{B}\right)\right]^{N}\right)
$$

where, $h(A)$ is the density function of the minimum of the sample $\left\{A_{1, \ldots}, A_{N}\right\}$. 